\title{
Index Insurance and Cash Transfers: A Comparative Analysis from Northern Kenya
}

\author{
Nathaniel D. Jensen ${ }^{\dagger 1}$, Christopher B. Barrett ${ }^{\dagger}$ and Andrew G. Mude ${ }^{\dagger}$ \\ ${ }^{\dagger}$ Cornell University, Ithaca, NY, USA; ${ }^{\star}$ International Livestock Research Institute, Nairobi, Kenya
}

December, 2014

\begin{abstract}
Cash transfers and index insurance have become popular interventions by development agencies worldwide. But they operate in radically different ways. In principle, these could offer complementary or substitute means of improving households' well-being, both through direct payments and through induced behavioral change. Surprisingly, little is known about these programs' comparative impacts on participant behavior or well-being, nor about their prospective interactions. This paper exploits four years of household panel data from northern Kenya, where the government launched a Hunger Safety Net Program (HSNP) offering cash transfers just prior to the commercial launch of an index-based livestock insurance (IBLI) product. By exploiting the known selection mechanism behind HSNP participation and the randomization of IBLI extension education and premium discounts, we are able to make novel comparisons of the causal impacts of each type of program among the same population at the same time, which spans a catastrophic drought. We find that both programs benefit participants, but there is no evidence of positive synergies between the two programs. HSNP participation increases the likelihood that a household maintains mobility, an important pastoral production strategy, and improves child health, as indicated by a mid-upper arm circumference (MUAC). IBLI coverage increases expenditures on livestock health services, milk production, MUAC, and income per adult equivalent. Standardizing the estimated benefits by total program costs reveals that the two programs perform comparably, while from a marginal cost perspective the IBLI program has impacts per unit of expenditure at least an order of magnitude greater than HSNP.
\end{abstract}

JEL CODES: D60, I38, O00

\footnotetext{
${ }^{1}$ Corresponding author: Nathaniel D. Jensen ndj6@ cornell.edu.

The survey data described in this research were collected by a collaborative project of the International Livestock Research Institute, Cornell University, the BASIS Research Program at the University of California at Davis, and Syracuse University. Data collection was made possible, in part, by support provided by the generous funding of the UK Department for International Development (DfID), the Australian Department of Foreign Affairs and Trade and the Agriculture and Rural Development Sector of the European Union through DfID accountable grant agreement No: 202619-101, DfID through FSD Trust Grant SWD/Weather/43/2009, the United States Agency for International Development grant No: EDH-A-00-06-0003-00, the World Bank's Trust Fund for Environmentally and Socially Sustainable Development Grant No: 7156906, and the CGIAR Research Programs on Climate Change, Agriculture and Food Security and Dryland Systems. All views and interpretations expressed in this document are those of the authors and not necessarily those of the supporting or cooperating institutions. The authors thank the all persons who contributed to this survey and its various sub-processes, especially Michael Carter, Sommarat Chantarat, Eddy Chebelyon, Philemon Chelanga, Brian Dillon, Diba Kone Galgallo, Anne Gesare, Munenobu Ikegami, Sarah Janzen, Amy Kahn, Samuel Mburu, John McPeak, Oscar Naibei, Robert Ouma, Nishith Prakash, Megan Sheahan, Mohamed Shibia, the interviewees, enumerators, and supervisors. Any remaining errors are our sole responsibility.
} 


\section{Introduction}

For poor rural households in developing countries, the risk of economic, climatic, social, or other shocks to their livelihoods is a daily threat, and its realization can be a devastating reality. The prospect of such shocks drives households to pursue risk-reducing strategies, often at the cost of significant foregone income (Carter 1997; Morduch 1995; Rosenzweig \& Binswanger 1993). When shocks do happen, they not only reduce household income but can compel coping behaviors with long-term negative implications, for example, distress sales of productive assets, withdrawal of children from school, or reducing nutrient intake by skipping meals. Such ex ante and ex post risk management strategies can trap families in cycles of poverty. ${ }^{2}$

Development agencies and governments have been quite active in the past decade or two with interventions that aim to address these structural challenges. Social protection programs represent one intervention approach that is gaining acceptance as a cost-effective strategy for alleviating poverty in developing nations. ${ }^{3}$ Although these programs use many different approaches, they commonly emphasize risk and vulnerability reduction among the poor (Conway, de Haan \& Norton 2000).

Social assistance, which directly transfers resources, and social insurance, which supports access to risk pooling, represent two distinct, but common approaches to social protection. While much has been learned about the impacts of social assistance in the form of cash transfers, much less is known about how those impacts compare with alternative programs such as socially supported insurance. Yet, to fully understand the value of a specific program or approach we must also take into account the opportunity costs of diverting funds from other potential programs that could also yield welfare gains.

This study compares two social protection programs, examining their behavioral and welfare effects on participants and then situating those impacts in light of their average and marginal costs to the public through government and donor funding. More precisely, we study the impacts of two interventions in northern Kenya: the Hunger Safety Net Program (HSNP), a publically funded and administered cash transfer program, and Index Based Livestock Insurance (IBLI), a privately administered but publically supported livestock insurance program. Although both programs were introduced contemporaneously with the aim to improve lives in northern Kenya, the country's poorest region, they take markedly different approaches. The government-run, donor-funded HSNP provides targeted participants with a regular source of income. IBLI is privately run but also relies on some initial donor funding to provide commercial policy holders with indemnity payments to compensate for irregular, catastrophic losses of livestock, the main productive asset. Using four rounds of annual household panel data collected between 2009-12, the known targeting criteria of HSNP, and the randomization of inducements to purchase IBLI, we compare the causal impacts of each program, explore prospective interaction effects between them, and assess their benefits along specific household characteristics per unit public cost of each program.

We find that households with IBLI coverage or a history of coverage increase investments in livestock health services, reduce herd sizes, and experience a large increase in milk productivity and total milk income. Insured households also increase livestock offtake during seasons with low livestock mortality

\footnotetext{
${ }^{2}$ See the broad range of literature on poverty traps, for example Azariadis \& Stachurski (2005); Barrett \& Carter (2013); Barrett \& Swallow (2006); Bowles, Durlauf \& Hoff (2006); Carter \& Barrett (2006).

${ }^{3}$ As an example of the enthusiasm directed towards social protection programs, in 2007 the G8 Summit Declaration on Freedom of Investment, Investment Environment and Social Responsibility stated that "[s]ocial protection is an investment in a country's economic future and a cost-effective way of fighting poverty" (paragraph 28 ).
} 
rates, when livestock prices area at their highest. These results point towards reduced precautionary savings among the insured, leading to greater intensification through yield and income increasing investments and marketing patterns. IBLI coverage leads to improved welfare as measured by income per adult equivalent (AE) and child health, as measured by mid-upper arm circumference (MUAC), although its impacts on MUAC are only statistically significant once we have controlled for HSNP participation. In comparison, HSNP participation increases the likelihood that a household is partially or fully mobileand has a positive impact on child health by increasing MUAC. There is no evidence of positive synergies from being a client of both programs improves outcomes, although this may be because there is only minor overlap in coverage between them. Finally, an analysis of the estimated impacts per unit of public cost finds that the two programs produce average benefits that are similar in magnitude, while IBLI produces far greater benefits with respect to the marginal cost of an additional client.

The remainder of this paper is organized as follows. Section 2 provides background on cash transfers and index insurance. Section 3 provides background on pastoralists in northern Kenya and describes the IBLI product and the HSNP. Section 4 describes the data. Section 5 describes our empirical strategy. Results and a discussion are found in section 6. Section 7 concludes.

\section{Background}

\section{Cash Transfers}

One type of social assistance program — cash transfer programs - aims to address poverty by providing cash to the poor or vulnerable, guaranteeing them a minimum level of stable income. Cash transfers are meant to reduce poverty and vulnerability by increasing and smoothing household income. In theory, regular payments can help maintain basic levels of consumption, reduce the use of detrimental risk mitigation strategies, diminish reliance on destructive short-term coping mechanisms, and maintain or increase investments in human and productive capital.

A number of large-scale, long-term, and well-documented social transfer programs (e.g., Mexico's Progressa/Oportunidades, South Africa's Child Support Grant program, Brazil's Bolsa Familia, Colombia's Familias en Acción) have advanced our understanding of transfer programs. In a survey of over 25 cash transfer programs, Fiszbein and Schady (2009) find that transfers significantly reduced the poverty gap in Colombia, Honduras, Mexico, and Nicaragua. They also find evidence from multiple countries that transfer programs can have a variety of socially beneficial impacts on recipients in addition to reduced poverty, such as increasing household consumption, increasing enrollment of children in school, reducing the negative impacts of catastrophic shocks, and increasing the bargaining power of women. These changes can help reduce the number of households that fall into poverty and increase the number of households that climb out of poverty (Arnold, Conway \& Greenslade 2011).

However, less is known about the behavioral process by which transfers produce welfare impacts. Gertler, Martinez and Rubio-Codina (2012) provide some insight in this area by examining how transfers effect production and investment decisions by Oportunidades' participants in Mexico. The study finds that transfers increase investments in agricultural assets and leads to an observed increase in agricultural productivity and income. Similar results have been found elsewhere - for example in Malawi (Covarrubias, Davis \& Winters 2012) and Niger (Stoeffler \& Mills 2014) — but are far from ubiquitous. Cash grants have also been shown to have benefits in non-agricultural settings, increasing assets, work hours and earnings (Blattman, Fiala \& Martinez 2014). 
In addition to the direct effects that cash transfers have on current income, the promise of regular future transfers may also relax insurance constraints. Bianchi and Bobba (2012) find that participation in Oportunidades increases the likelihood of entering entrepreneurship and that the effect is more tightly linked to the promise of future transfers than to received transfers. Bianchi and Bobba argue that the cash transfers provide a buffer against future income shocks, inducing greater risk taking among participants.

Costs are one of the primary drawbacks of transfer programs. The public must shoulder not only the transfer itself but also the administrative and program costs associated with targeting, monitoring, and dispersing transfers. Targeting and monitoring costs can be substantial as they require up-to-date household-level data to determine eligibility. In addition, policy makers and the general public may balk at the prospect of beginning an entitlement program that can be difficult to end (Cain 2007). To have enduring impacts, transfers must either be perpetual or large enough that people can lift themselves out of poverty and become able to self-insure against future shocks.

\section{Social Insurance}

Weather related risk and shocks are major drivers of the high levels of poverty observed among smallholder farmers in developing countries. Many experts argue that insurance protecting against weather related shocks could help households cope with this risk (e.g., Alderman \& Haque 2007; Barnett, Barrett \& Skees 2008; Devereux 2001; Mahul \& Stutley 2010). Reduced risk exposure through insurance could free households from the need to practice costly self-insurance and protect them from shocks that might drive them into long-term destitution, while encouraging investment or adoption of newer technologies that they perceive as risky.

Publically supported or provided weather index insurance offers an alternative approach to social protection that, like cash transfers, has ignited considerable interest. Index products are designed to overcome supply side barriers thought to hinder access to conventional insurance, which is based on individual losses, for smallholder farmers in developing countries. Indices based on easy-to-observe signals that are likely to be highly correlated with agricultural catastrophes - such as precipitation or temperature - can be used to provide insurance with low overhead. In addition, index based polices are less burdened with monitoring and validation costs, obviate incentives for moral hazard, and may reduce the incidence of adverse selection.

Although index products seem promising, the past decade's wave of index insurance pilot programs have little to show in the way of empirical evidence of impact. Partially due to low demand and partially due to inadequate data, the research on welfare outcomes due to index insurance coverage is scarce. To the authors' knowledge, there are just three papers that use household-level data to empirically examine outcomes associated with index insurance coverage in developing countries. Two of them examine weather insurance for crops. Mobarak and Rosenzweig (2012) use an intent to treat approach to find that offering index insurance to rice farmers in India increases their likelihood of planting a higher risk/higher yield variety of rice. Karlan et al. (2014) find that Ghanaian farmers with rainfall index insurance increase investments in agriculture and that this response is much greater than in a comparable cohort of households that received a sizable cash grant. ${ }^{4}$ The implication is that agricultural investments are risk constrained in this population and that index insurance successfully relaxes that constraint, perhaps more effectively than cash transfers.

Janzen and Carter (2013) study the same index based livestock insurance product in Kenya that we explore. They find that, in the wake of indemnity payments triggered by a massive drought, wealthy households with insurance foresee selling fewer livestock (their main productive capital) than their uninsured

\footnotetext{
${ }^{4}$ The Karlan et al. (2014) study is somewhat unique in that uptake was much higher than in other studies. The study also includes randomized cash and insurance grants, which help to identify if households are risk or cash constrained.
} 
counterparts and that poor insured households expect to reduce consumption less in the coming periods than the uninsured poor. ${ }^{5}$ In addition, Janzen and Carter find evidence that households with insurance are better able to smooth consumption during the drought (pre-indemnity) than the uninsured.

This evidence notwithstanding, the generally low product uptake and the lack of rigorous impact evaluations has led some to question the building excitement around index insurance and has elicited criticism of the amount of funding that has been directed towards index insurance. Binswanger-Mkhize (2012) argues that the potential of index insurance to reduce poverty is low since better-off farmers already have successful risk mitigation strategies while poorer farmers are unable to afford the insurance or are unwilling to experiment with untested new products. Implicit in this argument is that even if index insurance could theoretically help people, only a small segment of the population will realistically benefit and it is unlikely to be the poorest. In addition, as nearly all studies of index insurance point out, households that have index insurance coverage almost certainly continue to be exposed to basis risk, which can be quite sizable (Jensen, Barrett \& Mude 2014; Leblois, Quirion \& Sultan 2014).

\section{Setting and Interventions}

This research examines the impact of two interventions undertaken concurrently among pastoralist households in the arid and semi-arid region of Marsabit in northern Kenya. This section begins with background on pastoralists in this region in order to better place the interventions and their potential outcomes. We focus on environmental and production factors that are critical to pastoralists' livelihoods and that are potentially sensitive to HSNP or IBLI participation. We then provide a description of the HSNP and IBLI programs.

\section{Pastoralists in Arid and Semi-Arid Lands}

Greater than half of the earth's surface is arid or semi-arid, and for much of it grazing is the only suitable low-input method for food production (Child et al. 1984). ${ }^{6}$ Characterized by a dependence on livestock grazing for a large percent of the household economic portfolio, pastoralism has evolved as a livelihood strategy in many arid and semi-arid lands where cropping is precarious and low concentrations of resources have held population densities low (FAO 2001; Naimir-Fuller 1999). According to the FAO, there are an estimated 20 million pastoral households worldwide (FAO, 2001). Although livestock provide a means for these households to generate a livelihood in marginal landscapes, they also come with risks. Because they are often the most productive asset that a pastoralist can own and may represent one of very few savings options, livestock usually constitute a large portion of a household's productive capital and wealth, yet are vulnerable to climate shocks, disease, and predation.

Transhumant pastoralists are distinguished by regular cyclical movements of herds between seasonal pastures, satellite pastures. Opportunistic grazing and forage tracking associated with livestock mobility and satellite camps provides low-cost fodder, contributes to pasture sustainability by allowing degraded pastures near base camps to rest, manages risk, and provides access to different markets (Niamir-Fuller 2005). These mobile strategies have been found to increase average herd productivity, reduce production

\footnotetext{
${ }^{5}$ Neither effect (change in distress sales/consumption) is apparent in the uninsured (poor/rich) subsample.

${ }^{6}$ Arid and semi-arid regions are defined by those areas where annual precipitation falls between 0-300 mm and 300-600 mm, respectively (FAO 1987). Areas receiving below $500 \mathrm{~mm}$ of annual are generally unsuitable for cropping, suitable only for rangelands (Brown 1963).
} 
variability due to climate shocks (Niamir-Fuller 1999; Scoones 1994), and increase drought survival rates in northern Kenya (Little et al. 2008).

Among pastoralists in northern Kenya, which is where this study takes place, greater herd size is associated with both higher per capita income and lower income variation (McPeak, Little \& Doss 2011). Greater predrought herd size is also associated with increased post-drought herd size (Barrett et al. 2006; Lybbert et al. 2004; McPeak 2005), indicating that herd accumulation is both a rational economic investment and an effective strategy for ensuring that the household can rebuild its productive capital after climate shocks. In addition, herd size may reflect a precautionary savings response to uncertainty in environments with incomplete financial markets, such as northern Kenya. Even where there is access to other financial assets, herders do not necessarily view them as lower risk than livestock (McPeak 2005).

Furthermore, herd size and mobility are entangled and appear to play an important role in the long-term well-being of pastoralist households. Accessing the benefits of mobility requires labor to tend the satellite herd and removes livestock resources from the base camp (Toth 2015). For households with few livestock or little labor, the costs of mobility are typically too high. The result can be that households with small herds are unable to take full advantage of a primary asset of arid and semi-arid lands, extensive common pool rangelands. In both Ethiopia and Kenya, sedentary households, small herds, and extreme poverty are inextricably associated due to the feedback between mobility and herd size in an environment where there are few other livelihood options (Barrett et al. 2006; Little et al. 2008; Lybbert et al 2004).

Investing in livestock inputs can also be an important pastoral strategy. Veterinary services have been shown to be a highly effective means for reducing livestock mortality and for maintaining herd lactation rates (Admassu et al. 2005; Homewood et al. 2006; Sieff 1999). Since a large majority of household income is earned from milk production and livestock are the primary store of household wealth, this makes veterinary care a high-return investment. In Kenya, uptake of veterinary services is nonetheless low among pastoralists. Households report that access to providers, price, access to cash, and poor knowledge of veterinary services play a large role in determining use (Heffernan 2001).

Livestock markets could theoretically offer a mechanism for increasing income and mitigating shocks. Unfortunately, livestock markets in arid and semi-arid regions suffer from a high degree of both supply and price variability that reduces the benefits of market participation for pastoralists in response to droughts. During droughts, access to rangeland water and feed falls, reducing both the health of the livestock and the production of animal products on which households depend. These environmental factors may compel households to sell animals, both to meet the income deficit left by a loss in livestock byproducts (Coppock 1994) and to avoid loss due to mortality (Holtzman \& Kulibaba 1994). Since climatic shocks, such as drought, often take place over large regions, many households suffer the same drought and respond in a similar manner. The associated sudden increase in livestock supply and drop in animal productivity causes prices to fall sharply, especially where markets are isolated (Barrett et al. 2003). Post drought, herders who could benefit by using markets to help rebuild their herds face low supply, high prices and limited liquidity with which to restock commercially. Thus, depending on a number of market and environmental factors, households may find it beneficial to increase sales during drought, smoothing income, or to reduce sales during droughts, smoothing assets. The empirical evidence from of arid and semi-arid areas of Africa points towards asset smoothing behaviors dominating (Barrett et al. 2006; Carter \& Lybbert 2012; Fafchamps, Udry \& Czukas 1998; McPeak 2004).

In summary, in northern Kenya successful pastoralists maintain herds large enough to maintain mobility, even over drought years with high mortality. Households that fall below a herd size mobility threshold are likely to struggle for a host of reasons associated with their inability to effectively draw on the scarce 
resources of the environment. The use of veterinary services is limited but high return, especially for maintaining herds' lactation rates on which current income heavily depends. When it comes time to sell livestock, it is far better to do so in non-drought periods, when animals fetch much higher prices. In this setting these behaviors are key mechanisms through which social assistance interventions can generate welfare gains among the target population.

\section{Hunger Safety Net Program (HSNP)}

Phase I of HSNP in Kenya provided long-term, unconditional, scheduled cash transfers to 69,000 households in the four poorest districts of Kenya: Marsabit, Mandera, Turkana, and Wajir. Phase I was rolled out across communities starting in April 2009 and continued through the duration of this study, ending in June 2013. ${ }^{7}$ Participating households were to receive Ksh 2,150 (about USD 29) every 2 months for a period of 2 years. ${ }^{8}$ Payments were planned to take place in about 200 of 434 total sublocations in the four districts. ${ }^{9}$ The program aimed to target $40-50 \%$ of the population in each of the sublocations.

The objective of Phase I was to reduce food insecurity in those households that received transfers, evaluate the effectiveness of the program, and to evaluate three different targeting mechanisms that were used to determine which households received transfers. To that end, Phase I was implemented using an experimental survey design, randomly designating 24 'treatment' sublocations from a pool of 48 selected sublocations. Those treatment sublocations were to recieve transfers during the first two years of the program while the remaining 24 'control' sublocations received payments only during the final two years, as HSNP began to scale. Each treatment sublocation was also randomly assigned one of the following targeting mechanisms to determine who within each location was eligible for cash payment.

1) Social pension: All members in the community over the age of 54 years were eligible to receive transfers. Households could receive a transfer for each eligible member.

2) Dependency ratio: All households in which a certain percentage of the members are older than 55 , younger than 18 , disabled or chronically ill are eligible. ${ }^{10}$

3) Community based targeting: The community is instructed to select those households that are most food insecure. Up to half of the community's households are to be selected this way.

Only a single targeting mechanism was used in each community. Once a household was selected to receive benefits, it received transfers for the entire period unless the beneficiary chose to drop out of the program, died, or moved out of the area. Importantly, households did not graduate and there was no retargeting process in the community. ${ }^{11}$

\section{Index-based Livestock Insurance (IBLI)}

The IBLI product uses an index of predicted average livestock mortality rates developed by a team of researchers from Cornell University, the University of California at Davis, and the International Livestock

\footnotetext{
${ }^{7}$ Phase II of the program began in 2013. For more details, see http://www.hsnp.or.ke/.

${ }^{8}$ In 2009 , Ksh 2,150 was greater than $50 \%$ of monthly household consumption for about $32 \%$ of the households whose data we study. The transfers were increased to Ksh 3,000 in September 2011 and then to Ksh 3,500 in March 2012 due to drought and inflation. The 2009 average exchange rate was USD 1=KSH 74.74.

${ }^{9}$ A sublocation was the smallest administrative jurisdiction in Kenya, followed by location, division, district and province.

${ }^{10}$ The initial HSNP literature stated that in communities using dependency ratio targeting, households in which $57 \%$ of the members are older than 55, younger than 14, disabled or chronically ill are eligible. We use a more recent definition (younger than 18) that was also used in the publically available HSNP impact evaluation (Hurrell \& Sabates-Wheeler 2013). We retain the 57\% threshold since no information on the threshold is provided in the more recent HSNP literature.

${ }^{11}$ For further information on the targeting and selection process of HSNP, see Hurrell, MacAuslan and Merttens (2008) and Hurrell and Sabates-Wheeler (2013).
} 
Research Institute (ILRI), as described in Chantarat et al. (2013). The team used historic, remotely sensed, Normalized Difference Vegetation Index (NDVI) observations and livestock mortality rates to develop a response function that predicts livestock mortality rate from NDVI data. NDVI is a model index signal as it is exogenous to individual actions, available freely, provides frequent spatially dense observations in near real time, and has more than 20 years of archived data with which to estimate the response function and simulate the underlying distributions needed for pricing an insurance product.

The Marsabit district of northern Kenya was divided into five insurance divisions that correspond to established and commonly recognized administrative boundaries, so as to reduce the likelihood of consumer confusion (Figure 1). A separate index is calculated in each insurance division corresponding to its NDVI values. If a division's index predicts livestock mortality rates greater than the $15 \%$ contractual strike rate, then insured households within that division receive indemnity payments equal to the product of the value of livestock insured and predicted livestock mortality rate less the strike. So the strike rates function like a deductible in conventional insurance and IBLI provides insurance against the covariate catastrophic loss layer of livestock mortality risk.

Two private local insurance underwriters, APA and UAP, have commercialized and sold IBLI through local informants and sales agents. IBLI sales windows occur in the two months preceding each of the semi-annual rainy seasons. Figure 2 illustrates the IBLI calendar. Although there are two sales windows every year, an IBLI policy provides coverage for 12 months so that policies may overlap or accumulate. Policies are purchased in tropical livestock units (TLUs), which converts different types of livestock-goats, sheep, cattle, and camels, in this case — into a common unit based on metabolic weight. ${ }^{12}$

Pilot grant funding provided field support for commercialization, transportation for sales agents, and direct premium subsidies. The subsidies took two forms. The first was a universal reduction in the insurers' loaded premium rate resulting in an effective premium subsidy of $40 \% .{ }^{13}$ The second subsidy is provided through a series of randomized discount coupons that were distributed before each sales season to participants in the household survey, which was launched to evaluate the impact of IBLI (on which, more in section 4).

Demand for IBLI has been comparable to or greater than that found in other studies of index insurance in developing countries, with $41.9 \%$ of surveyed households purchasing IBLI at some point over the period of study and average seasonal uptake at $16.2 \% .{ }^{14}$ Over the four sales windows included in this research, 3,293 policies have been sold for a total insured value of about USD 1.4 million. Severe drought conditions triggered indemnity payments to policy holders in all five insurance divisions in October-November 2011 and again in two of the five divisions in March-April 2012, within our survey period.

\section{Data}

This analysis uses four rounds of household panel data from the Marsabit region collected by the ILIB project team. The baseline was collected in October-November 2009, one to two months before the IBLI

\footnotetext{
$121 \mathrm{TLU}=0.7$ camels $=1$ cattle $=10$ goats or sheep.

13 This subsidy remained constant from IBLI's January 2010 début through the period examined in this research, but has since decreased.

${ }^{14}$ Uptake among studied households (e.g., surveyed, provided with additional education, included in price incentive experiments) at actuarially fair premiums is commonly less than $20 \%$ per season and often much below that (e.g., Giné, Townsend \& Vickery 2008; Karlan, et al. 2014; Mobarak \& Rosenzweig 2012). At highly subsidized rates, uptake generally increases but is much below $100 \%$ even when the expected indemnity payments are much greater than the premium rate. Among the general population (nonstudied households) uptake is usually negligible.
} 
pilot was announced and the product became available in January of 2010 and six months after the first HSNP transfers started. Three annual follow-up rounds were collected each October-November thereafter.

The IBLI survey sites were selected according to specific parameters set to help learn about IBLI and how HSNP transfers interact with IBLI. Sixteen communities were selected to represent the wide range of ecological and market conditions found in the Marsabit region and stratified to ensure that both HSNP targeted and non-targeted communities were included (Figure 1). Proportional household sampling was done at the community level. Within communities, households were selected by random sampling, stratified by wealth group based on initial livestock holdings. For more information see https://livestockinsurance.wordpress.com/publications/, where the data and codebook can be found.

The survey tool included a wide variety of questions on household demographic and economic characteristics. It emphasizes livestock related data, such as herd composition and detailed monthly livestock intake and offtake. A description of the variables used in this study is found in Appendix A and summary statistics are found in Table 1.

A total of 924 households were surveyed in each round with attrition rates less than $4 \%$ between rounds. As a precaution against attrition bias, we reweight our observations using an established inverse weighting procedure (Baulch \& Quisumbing 2011; Fitzgerald, Gottschalk \& Moffitt 1988; Wooldridge 2002). This process requires that the baseline data are observed, so we restrict our sample for the remainder of this manuscript to those 924 households that participated in the baseline survey. See Appendix A for more details on our test for attrition bias in the estimates and the procedure used to reweight household observations.

\section{Selection into HSNP Participation}

HSNP payments started in April 2009, about six months before the first round of the IBLI household survey. By the time that the first round of the IBLI survey was collected, 154 households, from 5 of 16 survey communities in the balanced panel, had received transfers. The HSNP rollout added 120 participating households in 3 communities between the 2009 and 2010 survey rounds, 80 households in 1 community between the 2010 and 2011 rounds, and 10 households between the 2011 and 2012 survey rounds (Table 2). ${ }^{15}$ Although the survey data were collected annually, an HSNP implementing agent provided data on initial transfer dates for each community so that we can accurately estimate the number of payments that a household received in each season.

There are a few abnormalities worth noting in the transitions described by Table 2. First, although transfers were originally meant to last for only two years, there is no obvious cessation in transfers, even in the cohort that started receiving transfers in April 2009. According to HSNP documentation, the transfers were extended past their original mandate of two years due to the 2011 drought. It is our understanding that the project continued to make transfers to all participating households that have not opted out or lost eligibility (from death or moving) during the entire period examined in this research (2009-2012). ${ }^{16}$

In addition, there are some inconsistences in reported HSNP participation (as reflected in non-constant diagonal values among participants in Table 2). 56 households appear to drop out of the program and in 22 occasions participation varies over time. Finally, in 25 instances, households outside of HSNP target

\footnotetext{
15 To examine the rollout progression and adherence to selection criteria of HNSP among the survey population, we restrict the data to the balanced panel $(\mathrm{N}=832)$, so that we have data on household characteristics during targeting and when each household began receiving transfers.

${ }^{16}$ According the program design, the only way to lose benefits is to opt out, to move out of the community, or for the recipient to die.
} 
communities report receiving HSNP transfers. In all cases, we use the household's reported participation, even when those reports do not coincide with the HSNP targeting or rollout parameters. We remain agnostic about the veracity of these discrepancies, but potential causes, in addition to prospective measurement error, include unobserved household structures (e.g., households spread across multiple communities), migration (e.g., household moves out of HSNP target community but does not report the move to HSNP), or intrahousehold dynamics (e.g., changes to a survey respondent's knowledge of transfers received by another household member).

Each treatment community was randomly assigned a single, known targeting scheme: pension, dependency ratio, or community designation. ${ }^{17} \mathrm{We}$ observe age and dependency ratio. Community designated need is simulated by regressing HSNP participation onto a set of target household characteristics described in the HSNP monitoring and evaluation strategy (Hurrell, MacAuslan \& Merttens 2008), within community designation communities. The parameter estimates from that initial regression are then used to generate propensity to participate scores and those with an estimated propensity of greater than $50 \%$ are categorized as eligible. See Appendix B for a full description of this process.

If targeting is perfect, transfers are independent of household characteristics conditional on those characteristics associated with targeting and location. The four year weighted average adherence to selection is $85.9 \%$ among the general population and $76.5 \%$ among households within target communities while transfers were taking place there. Accuracy was greatest in the social pension group, which targets by age. A detailed analysis of the accuracy of each targeting scheme is found in Appendix B.

From the perspective of the impact evaluation that follows below, the key point is that HSNP cash transfers were expressly targeted based on exogenous threshold in household characteristics. Even though adherence to the criteria is imperfect in the survey data, the strong match between the exogenously specified selection criteria threshold and self-reported receipt of cash transfers under HSNP enables us to instrument for HSNP participation using the known, exogenous eligibility threshold in order to produce clean estimates of the causal impact of HSNP receipt on various behavioral and welfare outcome variables of interest. We will discuss this in greater detail in section 5 .

\section{IBLI Uptake and Indemnity Payments}

IBLI first became available for purchase in January 2010. More than a quarter of surveyed households purchased IBLI during that first sales window. Uptake and average coverage levels fell in the following sales windows but a significant portion of the survey households continue to purchase IBLI coverage in every season that it was available (Table 3). $41.9 \%$ of surveyed households purchased IBLI in at least one round. The average observed purchase was 3.15 TLUs. There were no sales during the August-September 2010 or January-February 2012 sales windows due to logistical complications among the insurance providers.

Due to severe drought, indemnity payments were made in all four survey divisions after the long rain/long dry season (LRLD) in 2011 season and in Laisamis and Marsabit Central divisions after the short rain/short dry season (SRSD) in 2011 (Table 4). As a reminder, policies last for 12 months so that households that purchased coverage during either the January-February 2011 sales widow or the August-September 2011 sales windows received indemnity payments during the SRSD 2011 indemnity payments.

17 The targeting criteria for each target community were drawn from reports published on the HSNP website (http://www.hsnp.or.ke/) and meeting notes acquired by the authors. Those criteria were then corroborated by implementing personnel in Marsabit in August, 2012. 


\section{Costs of program provision}

Phase one of the HSNP lasted from 2009 until June 2013. The HSNP website (http://www.hsnp.or.ke/) states that "[f]unding was provided by DFID and AusAID, to a total of GBP 40.5 million [Ksh 4.70 billion at 2009 exchange rates]. The government's contribution during phase one was primarily in hosting the Secretariat, providing policy direction, and facilitating work on the ground." We cannot locate estimates of the costs of support provided by the Kenya government. Omitting (the likely non-trivial) administrative and facilitation costs borne by the government, the total costs of providing transfers to 69,000 households was about Ksh 68,100 per participant household. ${ }^{18}$ These costs are prorated to reflect the period used in this analysis, which ends in March 2012. By March 2012 the program had provided transfers to 57,811 households and spent a total of Ksh 2.7 billion. ${ }^{19}$ The total prorated program cost per participating household was Ksh 47,600 (about USD 640 at 2009 exchange rates).

The IBLI pilot in Kenya was funded through grants from DFID, USAID, AusAID, EU, World Bank, and the Global Index Insurance Facility (http://livestockinsurance.wordpress.com/ibli-kenya/). The total program costs for the four years of operation considered in this research are estimated to be about KSH 99 million. ${ }^{20}$ Of that, a fairly large portion went to the initial product development and for evaluation research led by ILRI. Importantly, some of the ongoing overhead costs of the program are borne by the insurance providers who offer the product commercially. ${ }^{21}$ We only consider public costs incurred by governments (including foreign donors). By the end of the final sales round considered in these data (August/September 2012) there had been 3,293 contracts sold, at an average cost of KSH 30,100 per contract. ${ }^{22}$ The average number of contracts purchased by those that purchased IBLI in the survey data was 1.25 , so that the average total program costs per client in the survey is estimated to be $\mathrm{KSH} 37,600$.

The total program costs per participant is one metric for examining program cost. This indicator has drawbacks, for example placing no value on externalities such as infrastructure support or research, and represents an upper limit for the cost per client because it includes fixed costs and thus may inflate average costs under future operations as compared to a pilot program intentionally run at suboptimal scale during an evaluation period. In addition, both programs continued beyond the period examined by this research so that our estimates of total program costs per participant, which rely partially on budget items rather than expenditures, including funds that may not have been spent by the final period studied. These important shortcomings notwithstanding, the coarse benefit-cost indicators we use are informative nonetheless.

The marginal cost of an additional client offers an alternative cost metric, but necessarily omits the program's fixed costs. The marginal cost of an additional HSNP participant is the sum of transfers that the participant receives. By the final season used in this analysis, the average HSNP participant had received 13.9 transfers with a total real value (2009) of $\mathrm{KSH} 31,700$.

For IBLI, the marginal cost of an additional client is the total subsidies captured by that client by the end of our study period. As mentioned above, donors provide a fixed premium subsidy on all purchases and a variable subsidy provided through the discount coupons randomly distributed to $60 \%$ of the survey households by the research team. The non-transferrable coupons were distributed to about 550 households

\footnotetext{
${ }^{18}$ The number of participants $(69,000)$ is drawn from the HSNP website http://www.hsnp.or.ke/.

${ }^{19}$ Figure from internal HNSP documents. The authors prorated the 2011/2012 budget to reflect only 8 months (July-February) of the July 2011-June 2012 budget cycle.

${ }^{20}$ Andrew Mude, the IBLI project leader, estimates that the four year (2009-2012) costs were USD 1.3 million, or KSH 99 million using the 2009 average exchange rate of USD $1=\mathrm{KSH} 74.74$.

${ }^{21}$ Andrew Mude, the IBLI project leader, estimates that the insurance companies currently contributes 5-20\% of program costs.

22 J/F 2010: 1,974 contracts; J/F 2011:595 contracts; A/S 2011: 509 contracts; A/S 2012: 216 contracts
} 
semi-annually and provide a premium discount of between $10 \%$ and $60 \%$ for up to 15 TLUs of coverage per household. Coupons were good for one period only and a new random draw of discounts took place each season. The average household that purchased IBLI coverage in this data, bought coverage on a total of 3.25 TLUs during the sample and sales seasons. ${ }^{23}$ They received the fixed subsidy on all purchases and an additional discount provided by the discount coupon, averaged $29.7 \%$. Accounting for variation in premium values between division and inflation, the average purchaser had captured about KSH 1,579 in premium subsidies by the final survey period. ${ }^{24}$

\section{Variables of Interest and Econometric Strategy}

This research aims to investigate what, if any, impacts IBLI coverage and HSNP transfers have had on the behaviors and welfare of pastoralist households. To that end, we use a number of different dependent variables that can be broadly classified as indicators of coping strategies, production strategies, production outcomes, and welfare. In the following discussion, we refer to those as outcome variables and symbolically represent them by $y_{i, t}$ for outcome $y$ for individual $i$ in season $t$.

We use four variables of interest (VOI) to estimate the impacts of program participation: a dummy variable indicating that the household is a current HSNP participant $\left(H S N P_{i t}\right)$, current IBLI coverage $\left(I B L I_{i t}\right)$, measured in TLUs insured, lagged cumulative seasons as an HSNP participant $\left(H S N P C_{i t}=\sum_{s=1}^{t-1} H S N P_{i s}\right)$, and lagged cumulative seasons with IBLI coverage $\left(I B L I C_{i t}=\sum_{s=1}^{t-1} I\left(I B L I_{i s}\right)\right.$ where $I\left(I B L I_{i s}\right)=$ $\left[\begin{array}{ll}1 & \text { if } I B L I_{i s}>0 \\ 0 & \text { if } I B L I_{\text {is }}=0\end{array}\right] \cdot{ }^{25}$ Current HSNP participation and IBLI coverage are intended to capture behavioral changes associated with changes to risk exposure due to assured HSNP transfers or IBLI coverage as well as the income/liquidity effects of paying the IBLI premium and/or receiving HSNP transfers in that period. Total periods of participation in each program provide a measure of the cumulative financial and behavioral effects on household outcomes. The two cumulative variables are lagged by one season so that the current season is not double counted.

Our initial analysis begins by examining each of the programs separately. The reduced form model is described in equation (1) where OI $_{i t}$ is the vector of the two HSNP or IBLI program variables of interest, $x_{i t}$ is a vector of household characteristics, $c_{i}$ is the household's time invariant fixed effect, and $\varepsilon_{i t}$ is mean zero random error.

$$
\begin{gathered}
y_{i t}=\beta_{0}+V O I_{i t}{ }^{\prime} \beta_{1}+x_{i t}^{\prime} \beta_{2}+c_{i}+\varepsilon_{i t} \\
V O I_{i t}=\left\{\left(H S N P_{i t}, H S N P C_{i t}\right),\left(I B L I_{i t}, I B L I C_{i t}\right)\right\}
\end{gathered}
$$

All four variables of interest are almost surely endogenous to both observed and unobserved household characteristics. Explicitly, the impact of having livestock insurance is likely to be correlated with unobserved variables that are also related to the outcome variables; for example, those who choose to purchase IBLI are also likely those who benefit the most from livestock insurance. ${ }^{26}$ Participation in HSNP is expressly non-random, targeted toward specific households. Although we can control for the targeting

\footnotetext{
${ }^{23}$ This estimate excludes the sales in August and September 2012, which are included in Table 3 but not included in this analysis, is as stated in the text.

${ }^{24}$ Figures are in real 2009 Kenya Shillings.

${ }^{25}$ We will use the term program participation broadly to include receiving HSNP transfers and/or purchasing IBLI coverage.

${ }^{26}$ This argument assumes that the purchaser has a good grasp of the product and her/his own expected outcomes. But selection issues remain even if that is not the case. So long as there exist unobservable characteristics that are correlated with both the outcome of interest and the IBLI purchase decision, the impact estimates will likely be biased if we assume exogeneity.
} 
characteristics and eligibility thresholds, Section 4 provides evidence that selection criteria are unable to account entirely for the participation so that even after controlling for targeting variables and eligibility criteria OLS estimates are likely to be endogenous. We therefore use an instrument variables approach to identify the local average treatment effect (LATE) of our four VOI. The remainder of this section describes those instrumental variables.

\section{HSNP}

Selection into the HSNP program is not random and therefore the targeting criteria may be correlated with the outcome variables of interest. The regression model must include controls for the selection criteria. Furthermore, there are households whose participation status does not match their edibility status. An analysis of adherence to selection indicates that about 23\% HSNP community members have an HSNP status that is inconsistent with their eligibility (Appendix B). ${ }^{27}$ Thus, we must allow for the possibility that households might have in some way manipulated the selection process to make themselves eligible for transfers. If such non-compliance or misreporting is associated with characteristics that impact both HSNP participation and the outcome variables, then participation is endogenous.

To address endogeneity of participation, we take advantage of exogenous variation in participation caused by the participation criteria. Formal eligibility is determined relative to a pre-specified, exogenous threshold of a continuous selection variable, either dependency ratio, age, or community selected need, depending on the criterion randomly assigned to the community. Because the eligibility threshold for each targeting dimension is exogenous, they provide variation in participation that can be used to identify the impacts of participation. This research exploits those exogenous thresholds to construct an intent to treat variable that is used as an instrumental variable to estimate the impact of transfers in an environment of both imperfect selection and potential endogeneity of participation. Identification rests on the independence of the selection criteria thresholds from the outcome variables and a discrete increase in participation across the eligibility thresholds.

Appendix $\mathrm{C}$ examines the intent-to-treat variable to make sure that it is both exogenous and correlated with participation. Exogeneity is assessed by testing the distribution of household attributes for distortions along the eligibility dimensions that might indicate systematic misreporting of household characteristics in order to meet the eligibility criteria, which would weaken our argument that the thresholds are exogenous. We find no evidence of such behavior. ${ }^{28} \mathrm{We}$ also make sure to include flexible controls for household characteristics along the eligibility criteria dimensions (maximum household age, dependency ratio, and community determined need) in the primary estimations in order to allow for heterogeneous relationships between the eligibility criteria dimensions and outcomes. ${ }^{29}$ Relevance is confirmed by regressing HSNP participation onto the intent-to-treat variable (Coef. Est.= 0.615, Std. Err.=0.039, Table C2) and a flexible form of eligibility dimensions while controlling for variation in average division-period participation.

\footnotetext{
${ }^{27}$ As mentioned above, eligibly in those communities using community based targeting was estimated using a propensity to receive HSNP transfers score, developed by regressing HSNP participation on a set of household characteristics. See Appendix B for a full description of this process.

${ }^{28}$ It should be noted that the data used in this analysis are not the same as the data used by HSNP to determine eligibility is there is some prospect that eligibility changed between the HSNP program assessment and our data collection. See Jensen et al (2014) for a comparison of the HSNP and IBLI data.

${ }^{29}$ For each eligibility criteria dimension we include the household's attribute raised to the first, second, and third power. This flexible functional form allows for a nonlinear relationship between the eligibility criteria dimensions and outcomes. In some cases, such higher order forms can lead to instability in the parameter estimates, but an analysis including only first order controls arrives at the same conclusions as those presented in the results section below.
} 
Instrumenting for accumulated seasons as an HSNP participant follows directly from the above regression model. Accumulated seasons living in a targeted community and meeting the eligibility criteria of that community are the instruments. This can be thought of as including the entire sequence of past HSNP participation, instrumented in the same manner as current participation, in the outcome equation. The difference is simply that the sequence is aggregated into a single cumulative participation value for each period.

\section{IBLI}

Identification of the impacts of IBLI rests on exogenous variation in purchases associated with receiving a randomly distributed coupon that provided premium discounts for those that purchase IBLI. ${ }^{30}$ Balancing tests support the hypothesis that the coupons are random and correlated with demand (Table D1, Appendix D).

Current coverage is the result of purchases in either of the preceding two sales windows, which can be instrumented for by using the coupon discounts received (if any) in each of those two periods. Note that survey households received new coupons (or no coupon) randomly each sales period and the coupons were non-transferable among households or across sales periods. Similar to cumulative HSNP transfers, cumulative IBLI coverage can be instrumented by a variable that captures the accumulated seasons that the household received a discount coupon. The IBLI instruments are examined Appendix D. The discount rate provided by the coupon has a positive and statistically significant estimated impact on the amount of coverage purchased (Coef. Est.= 1.396, Std. Err.= 0.211, Table D2).

IBLI purchases also have a direct impact on expected income, which is equal to the difference between expected indemnity payments and premium payments made. If households purchase IBLI at a premium rate that is above the expected indemnity rate, their expected income is less than if they had not purchased IBLI. At below actuarially fair premium rates, IBLI purchases are associated with a de facto transfer to the household's expected income. Unlike HSNP transfers, which are more or less constant over the survey period, there is variation in the impact of IBLI purchases on expected income due to the distribution of discount coupons and because the expectation is a function of the quantity of coverage purchased. ${ }^{31}$ Controlling for this expected income effect of purchases would allow us to isolate the impact of the insurance coverage from the impact of the premium transactions. But, to do so requires instrumenting for both the amount purchased and the expected income effect, which is a first order function of the purchase level and our IV. The high degree of collinearity between the two instrumented variables results in highly unstable parameter estimates, so we abandoned that approach. Thus, our analysis of the impacts of IBLI capture both the income effects of premium transactions that are not uniformly actuarially fair and the risk mitigating effects of insurance coverage. But, we expect the direct income effects of IBLI purchases on the population to be small as the average purchase was associated with an implicit transfer of $636 \mathrm{KSH}$ and $99 \%$ of implicit transfers to purchasers are below 5,931 KSH for a 12 month contract. Although the larger

\footnotetext{
30 The IBLI research design also included a randomized education component that has a positive and significant impact on demand (Jensen, Mude \& Barrett 2014). Unfortunately, we cannot leverage the exogenous variation in demand associated with the education component in the main fixed effects estimates examined in this paper because there is no intertemporal variation in game participation. We do include participation in the educational game in a pooled IV analysis found in Appendix F, which offers a robustness check of the fixed effect estimates.

${ }^{31}$ Although there are small changes to the consumer price index and in the transfer size itself, which could be used to separately identify the impacts of participation and the impact of the transfer size, practically speaking, the variation is too small for us to separately identify the two.
} 
de facto transfers are quite substantial, even the greatest is smaller than the annual value of transfers received by HNSP participants and the average is smaller than a single HSNP transfer.

Our final analysis of both programs simultaneously uses an interaction between cumulative seasons of HSNP participation with cumulative seasons with IBLI coverage. We first establish that there is at least some overlap between the two programs. ${ }^{32} 140$ households purchased IBLI coverage while receiving HSNP transfers and 44 households did so more than once for a total of 194 observations. Although the overlap in clientele is not large, it is certainly feasible that 194 observations it could provide statistical evidence of prospective interaction effects. The interaction is instrumented using interactions between the instrumental variables that are used for each separately.

Our statistical analysis uses data from all four rounds of the survey but does not include data from the SRSD 2012 season because the outcomes of interest are estimated at the end of each season, which is not captured for SRSD 2012 in our data. We present and discuss the results of fixed effects instrumented variables estimates in the main body of the paper. Pooled instrumental variables estimates are included in Appendix $\mathrm{F}$ as a robustness check. Summary statistics of included covariates and the outcome variables are found in Table 1.

\section{Results}

This presentation and discussion provide results from the HSNP and IBLI regressions side by side. There are some differences between the two programs that will direct interpretation of parameter estimates. Very few HSNP participants stop participating in the program so that the HSNP variable is nearly always one when lagged cumulative transfers $\left(H S N P C_{i t}\right)$ are greater than zero. The IBLI current and cumulative variables are not so closely linked. Nearly half of the households purchase IBLI at least once but very few purchase in every season so that IBLI is often zero when $I B L I C_{i t}$ is greater than zero (59\% of observations). In addition, there is also a great deal of variation in level of coverage that we wish to examine, so that the current coverage variable for IBLI is not a dummy variable as it was for HSNP.

\section{Impacts on Coping Strategies}

We begin by examining the impact of HSNP participation and IBLI coverage on coping strategies in response to shocks. To do so, we construct an indicator variable that equals one during seasons in which a division's average livestock mortality rate is equal to or above $15 \%$. For both IBLI and HSNP, we estimate the impact that shocks and program participation have on livestock sales, allowing the impact of participation to vary between shock and non-shock seasons. Historic participation/coverage (HSNPC $i t$ / $\left.I B L I C_{i t}\right)$ is omitted from this analysis in order to focus on the impact of the household's current status.

Households sell more livestock during covariate shocks (row 1, Table 5) and there is no evidence that HSNP transfers or IBLI coverage effects those sales during shock seasons (Row 4, Table 5). ${ }^{33}$ There is strong evidence, however, that households with insurance coverage sell more livestock than do those without insurance (row 2, Table 5). The greater rate of sales takes place during seasons when livestock mortality is

\footnotetext{
${ }^{32}$ It could easily be the case that there is very little overlap if, as Binswanger-Mkhize (2012) hypothesizes, the poorest are unlikely to purchase insurance, while HSNP explicitly targets the poorest.

33 The marginal impact of program participation on livestock sales during shock years, is the sum of estimated parameters for current participation and current participation interacted with the shock indicator variable. We test if that sum is significantly different than zero for each program (row 4, Table7).
} 
low and thus when livestock prices are high, as discussed in section 2. These households are therefore increasing sales and timing sales more effectively to generate greater revenues and, presumably, profits.

There is a danger that these results are, in part, due to certain types of households (those purchasing IBLI) facing many or severe idiosyncratic shocks. To test the robustness of our findings, we re-estimate Table 5, with an individual measure of shock. These estimates are found in Table E1, Appendix E. The findings are consistent with those from the covariate definition of shocks; households increase livestock sales in response to shocks, neither HSNP participation nor IBLI coverage impacts livestock sales during shocks, and those households with IBLI coverage sell more livestock during non-shock seasons.

One potential explanation for increased market participation among the insured during non-shock seasons is that those households with insurance are more willing to respond to the threat of drought, increasing sales in anticipation of drought or more responsive to past droughts. This possibility is tested by examining household response to past and coming covariate shocks. Once again, the main impact of IBLI seems to be that it allows households to increase livestock sales in seasons that are not considered shocks (Table E2, Appendix E).

There are a number of other reasonable explanations for increased livestock sales with insurance coverage. Increased livestock sales associated with insurance coverage may be the result of reduced precautionary savings as predicted by Ikegami, Barrett \& Chantarat (2012). Alternatively, it could be that premium payments necessitate livestock sales outside of shock periods, when animals fetch higher prices (Barrett et al. 2003), as pastoralists typically hold little cash savings. Finally, households may use the insurance as a calculated gamble, buying insurance and selling their livestock before periods that they believe will trigger the index, effectively shorting the livestock market. If this final explanation were true and households were successfully predicting shocks, the impact of coverage on livestock sales before a shock would be positive, which it is not (Table E2). Thus we are left with the possibility that households respond to reduced uninsured risk exposure by drawing down precautionary savings, that IBLI coverage increases livestock sales due to the need to raise cash to pay premiums, and/or that they use IBLI as a lottery. We return to this discussion below as we examine the impact of program participation on production.

\section{Impacts on Pastoral Production}

Investments in production could take a number of forms including increased herd size, increased expenditures on veterinary services to safeguard and improve the productivity of one's pre-existing herd, or changing herding strategies. We therefore estimate the impact that IBLI coverage has on: herd size, expenditures for vaccines and veterinary care, as the best available measure to capture investments in existing productive capital, the ratio of animals kept at home (rather than in satellite camps), and the mobility status of the household to test for changes to herding strategies. ${ }^{34}$

We find that current HSNP participation increases the likelihood that households are partially or fully mobile (column 2, Table 6) and there is evidence that the effect accumulates over time so that longer-term participants are more likely to be partially or fully mobile than newer participants (column 1, Table 6). ${ }^{35}$ These findings are inconsistent with those of Hurrell and Sabates-Wheeler (2013), who found that HSNP had no impact on mobility, but are encouraging in the Marsabit region where sedentarization and poverty

\footnotetext{
${ }^{34}$ Data on water, supplementary feed, transaction costs, and other livestock expenditures were also collected but are very sparse. In every case, except for veterinary services, the median and mode expenditures were zero. In addition, expenditures on veterinary services has the highest mean, the lowest maximum and lowest standard deviation. Because our analysis inevitably examines variation around the average, we therefore restrict our expenditures to veterinary services.

${ }^{35}$ A linear probability model is used to estimate the impact of IBLI coverage on the partially or fully mobile binary variable.
} 
often go hand in hand. ${ }^{36}$ In addition, there is evidence that with greater duration of participation, households begin to enjoy increased milk production value per TLU (column 1, Table 6). ${ }^{37}$

Greater historic IBLI coverage leads to reduced herd sizes and increased expenditures on livestock veterinary services both in total and per TLU. These investments in existing productive capital bring significant increases in value of milk production and productivity (column 3, Table 6). Current depth of coverage also increases the value of production (column 4, Table 6). In light of increased expenditures on livestock health care and increased milk income, a reduction in precautionary savings seems the most credible explanation for the observed pattern of reduced herd size and increased livestock sales during nonshock seasons discussed above.

As a means of connecting IBLIs impact on herd size, livestock health services and milk production, we perform some back of the envelope estimates. To do so, we regress milk productivity (KSH/TLU/month) onto livestock health expenditures per TLU (KSH/TLU/year), household characteristics and household fixed effects. Livestock health expenditures per TLU are positively and statistically significantly (Coef. Est. $=0.188$, Std. Err. $=0.0850)$ related to milk productivity $(\mathrm{KSH} / \mathrm{TLU} / \mathrm{month})$. That is, the average annual per TLU health services expenditures $(91.0 \mathrm{KSH})$ are associated with a $204 \mathrm{KSH}$ increase in the value of annual milk output per TLU. ${ }^{38}$ Although this rate of return on veterinary expenditures is positive, it is too low for the increases in veterinary expenditures due to IBLI coverage to account for the entire increase in milk productivity that we observe in response to IBLI coverage. Thus, IBLI coverage must cause other unobserved changes in pastoral strategies, such as changes to herding strategies or in access to forage associated with herd shrinkage, that account for the increases in milk income we observed.

\section{Impacts on Welfare}

We now examine the impacts that each of these programs has on welfare. To do so, we construct a set of welfare indicators similar to those that are often examined by cash transfer programs. We use three indicators of household welfare (consumption per adult equivalent, an asset index, and monthly income) and three indicators of investments in children's human capital (ratio of school aged children enrolled in school, student absentee days, and mid-upper arm circumference [MUAC]). We also include a linear probability model to estimate of the impact of either program on the likelihood that a child has a MUAC score below $125 \mathrm{~mm}$, a threshold commonly used to indicate moderate acute malnutrition (MAM) in children ages 6-59 months. ${ }^{39}$

HSNP participation improves child MUAC scores and reduces the likelihood that a child's MUAC falls below the MAM threshold (column 2, Table 7). In both cases, sustained participation seems to have further positive impacts, although the coefficient estimate relating HSNPC to MUAC score is not statistically significant (column 1, Table 7). Persistent HSNP participation also seems to reduce both per AE

\footnotetext{
${ }^{36}$ Hurrell and Sabates-Wheeler (2013) use data collected by OPM for their analysis. A discussion of the differences between the OPM and IBLI data can be found at Jensen et al. (2014).

${ }^{37}$ The combined impact of past and current HNSP participation on milk production per TLU is positive and statistically significant at the $10 \%$ level by the $7^{\text {th }}$ season of consecutive participation. There is also some indication that initial HSNP participation increases livestock mortality rate, but that effect is immediately offset by the second season of participation. The average estimated impact of current HSNP participation while having already participated for a season is 0.028 with a standard error of 0.026 .

${ }^{38}$ An annual increase of $204 \mathrm{KSH}$ is equal to 12 times the monthly increase of $17 \mathrm{KSH}$.

39 The WHO does not currently state a global MUAC threshold for MAM in the way that it does for severe acute malnutrition, but the $125 \mathrm{~mm}$ threshold is used in practice for children ages 6-59 months by many intervention agencies, including the WHO (Annan, Webb \& Brown 2014; UNHCR WHO 2011, WHO 2011)
} 
consumption and asset wealth. ${ }^{40}$ Current IBLI coverage has a positive and statistically significant impact on income per adult equivalent (column 4, Table 7). Most striking, perhaps, is the stark lack of consistently positive, statistically significant impacts from either program.

If there are no time invariant household fixed effects, the fixed effects model is inefficient. It is possible that those potential inefficiencies obscure statistically significant impacts of program participation. As a robustness check, we re-estimate the analyses found in Table 6 and Table 7 using a pooled instrumental variables model. The pooled approach has the added benefit of tapping an additional instrumental variable for IBLI uptake: randomized participation in the educational game. The pooled estimates, found in Appendix F, confirm the general narrative of our primary analysis, although statistical significance changes in a few cases. Most importantly, there are no parameter estimates that are significantly different from zero in both models but opposite in sign and there is no overall indication of gains to efficiency.

\section{Heterogeneity in Impacts and Program Interactions}

One might rightly be skeptical of the implied homogeneity of impacts assumed by the above analysis. Previous studies from the region have found that herd size is related to coping strategies (Carter \& Lybbert 2012; Janzen \& Carter 2013), productivity (Barrett et al. 2006), livestock mortality rate (Lybbert et al. 2004), and willingness to pay (Chantarat et al. 2014). To better understand the distribution of impacts, we estimate the expected impacts allowing for variation in the average marginal impact of participation, and variation in participation rates across initial herd size (Appendix G). ${ }^{41}$ There is heterogeneity in expected outcome for milk productivity, where lower TLU households see significantly greater benefits from both IBLI and HSNP participation than do their more livestock wealthy counterparts; MUAC, where improvements due to HSNP participation is stronger among the lower TLU group and school absenteeism, where HSNP transfers reduce absenteeism among students from households with higher livestock holdings but not in lower TLU households (Table G2 \& Table G3). Examining the parameter estimates and the average rate of participation among the high or low TLU groups provides strong evidence that the heterogeneity in estimated outcomes is mostly due to variation in the marginal impact of participation rather than from variation in program participation across groups (Table G4). Such variation in response has important implications for the targeting of cash transfers. The findings for IBLI are interesting as they seem to point towards greater benefits among the livestock poor, which point towards the potential for a selftargeting effect.

In comparing the effects of HSNP and IBLI simultaneously on household welfare, we focus on the instrumented cumulative seasons with IBLI coverage and cumulative seasons receiving HSNP transfers. We also include an interaction between the two, in order to determine if any synergies appear between the two programs. We find that HSNP's impacts on child MUAC remain and IBLI's impact on child MUAC, which was positive but statistically insignificant when IBLI was examined without controlling for HSNP participation, is now statistically significant and more than twice the magnitude of the HSNP impact (Table 8). A positive impact of HNSP participation on school enrollment, which is hinted at in Table 7, now becomes statistically significant when we also account for IBLI participation. But, only in one case is there

\footnotetext{
${ }^{40}$ We have no hypothesis as to why persistent HSNP participation is associated with a reduction in asset wealth and consumption. It should be noted that in the case of the asset index, some of that reduction may be offset with current HSNP participation.

${ }^{41}$ Heterogeneity is allowed by estimating the reduced form equation (1) with an additional set of terms, the interactions between the VOIs and a dummy variable equal to one if the households initially has fewer than 10 TLUs.
} 
statistically significant evidence that the two programs interact, and we do not reveal strong evidence of impacts from either program that were not evident when they were analyzed separately.

\section{Cost}

To compare the relative cost effectiveness of the benefits of each program, we adjust estimated benefits by each program's public costs. We focus on the three production and welfare outcomes for which point estimates suggest welfare improvements under both programs for any level of participation: milk income, income per AE, and MUAC. Before discussing the benefits per unit costs, note that this analysis looks at the full public costs of HSNP and IBLI clients but only examines benefits along a few specific dimensions. This is not a comprehensive cost-benefit analysis, which would require that we observe and value all the costs and benefits associated with each program. Rather, this analysis examines the benefits associated with three specific outcomes only, adjusted by reported public program costs in order to provide a basis for comparison.

The average benefits among those that ever participated in the HSNP program or ever purchased IBLI coverage are estimated using the average VOI values among participant during the final period captured by our data (Table 9) and the parameter estimates in Tables 6 and 7. Table 10 summarizes the estimated average benefits and the unit costs of those benefits. Dividing the estimated average benefits by total reported public costs per client, the two programs produce changes in outcomes that are roughly the same in magnitude. But, the marginal cost of an additional client is much smaller for IBLI than HSNP. Dividing benefits by the marginal cost of an additional client, IBLI's benefits are consistently at least an order of magnitude greater than HSNP's.

These estimates bracket the true costs per client and highlight the variation in program cost structures. Cash transfer programs, such as HSNP, have overhead costs that go towards the targeting process and administration of transfers, but the service that they provide - cash — comes at cost and providers often provide little other support. Alternatively, offering an index insurance pilot in a region without insurance requires generating a product and developing a market for the new product, all at high initial sunk cost. The hope is that once public funds have overcome the largest fixed costs of product and market development, private enterprises will enter and begin to shoulder some or all of the operating variable costs. That has been the experience of IBLI in the initial pilot phase.

\section{Conclusions}

Cash transfers and publically supported insurance programs offer two very different approaches to providing social protection. This research finds evidence that both approaches can benefit clients, although their benefits differ in both manner and magnitude. HSNP targets and help the poorest households. In the northern Kenyan environment, where mobility and poverty are tightly linked, HSNP transfers increase or help maintain mobility and reduce the likelihood of moderate malnutrition among children, as indicated by MUAC.

Any household with sufficient access to cash can purchase social insurance where it is available. Those that purchase IBLI take advantage of their reduced risk exposure by drawing down their herd size and increasing investments in the productivity of their livestock, therefore increasing milk production and income. Although Jensen, Mude and Barrett (2014), find that HSNP participation increases the likelihood of IBLI uptake, such interactions do not produce statistically significant impacts on the welfare measures considered here. 
Thus, determining which approach best fits the aims of a social protection program depends both on the intended clientele, the program objectives, and its budget. Cash transfers provide income directly to targeted participants, which one might expect could be achieved with minimal fixed costs. Indeed, the fixed to variable cost ratio of HSNP is lower than that of IBLI, but HSNP does face considerable fixed costs. Although substantial program size may reduce the per client burden of initial sunk costs, transfer programs will always face the substantial variable cost burden of the transfers themselves. By contrast, our findings suggest that publically supported IBLI insurance can produce beneficial impacts on a scale similar to those associated with HSNP transfers, but with a very different cost structure. There are many up-front costs to developing a context-specific insurance policy, educating the public on the product, and marketing it. Such social insurance schemes also run the risk that low uptake will result in few households benefiting from the large initial public investments. For IBLI, at pilot scale, the ratio of total program costs per client to marginal cost of an additional average client is large, highlighting the heavy burden of fixed costs when the client pool is small. If the client pool for IBLI expands significantly - and the Government of Kenya proposes taking IBLI nationwide in 2015 - there is the potential for the total program costs per client to fall sharply due to the low marginal costs of subsidizing premiums. 


\section{References}

Admassu, B., Nega, S., Haile, T., Abera, B., Hussein, A., \& Catley, A. (2005). Impact assessment of a community-based animal health project in Dollo Ado and Dollo Bay districts, southern Ethiopia. Tropical animal health and production, 37(1), 33-48.

Alderman, H., \& Haque, T. (2007). Insurance against covariate shocks: The role of index-based insurance in social protection in low-income countries of Africa (No. 95). World Bank Publications.

Annan, R. A., Webb, P., \& Brown, R. (2014). Management of Moderate Acute Malnutrition (MAM): Current Knowledge and Practice. CMAM Forum Technical Brief.

Arnold, C., Conway, T., \& Greenslade, M. (2011). Cash transfers evidence paper. London: Department for International Development.

Azariadis, C., \& Stachurski, J. (2005). Poverty traps. Handbook of economic growth, 1, 295-384.

Barnett, B. J., Barrett, C. B., \& Skees, J. R. (2008). Poverty traps and index-based risk transfer products. World Development, 36(10), 1766-1785.

Barrett, C. B., \& Carter, M. R. (2013). The Economics of Poverty Traps and Persistent Poverty: Empirical and Policy Implications. Journal of Development Studies, 49(7), 976-990.

Barrett, C. B., Chabari, F., Bailey, D., Little, P. D., \& Coppock, D. L. (2003). Livestock pricing in the northern Kenyan rangelands. Journal of African Economies, 12(2), 127-155.

Barrett, C. B., Marenya, P. P., McPeak, J., Minten, B., Murithi, F., Oluoch-Kosura, W., Place, F., Randrianarisoa, J., Rasambainarivo, J. \& Wangila, J. (2006). Welfare dynamics in rural Kenya and Madagascar. Journal of Development Studies, 42(2), 248-277.

Barrett, C. B., \& Swallow, B. M. (2006). Fractal poverty traps. World Development, 34(1), 1-15.

Baulch, B., \& Quisumbing, A. (2010). Testing and adjusting for attrition in household panel data. CPRC Toolkit Note.

Bianchi, M., \& Bobba, M. (2012). Liquidity, risk, and occupational choices. The Review of Economic Studies, 129 (2): 697-752.

Binswanger-Mkhize, H. P. (2012). Is there too much hype about index-based agricultural insurance? Journal of Development Studies, 48(2), 187-200.

Blattman, C., Fiala, N., \& Martinez, S. (2014). Generating skilled self-employment in developing countries: Experimental evidence from Uganda. The Quarterly Journal of Economics, 129(2), 697-752.

Bowles, S., Durlauf, S. N., \& Hoff, K. (Eds.). (2006). Poverty traps. Princeton University Press.

Brown, L.H. (1963). The development of the Semiarid Areas of Kenya. Nairobi, Kenya: Ministry of Agriculture.

Cain, E. (2007). Addressing Chronic Poverty: Linking Social Protection, Economic Growth and EU Development Cooperation. Background briefing paper. The European Working Group on Social 
Protection and Decent Work in Development Cooperation \& The Grow Up Free from Poverty Coalition. Roundtable on Social Protection on International Poverty Day. Brussels, $17^{\text {th }}$ October 2007.

Carter, M. R. (1997). Environment, technology, and the social articulation of risk in West African agriculture. Economic Development and Cultural Change, 45(3), 557-590.

Carter, M. R., \& Barrett, C. B. (2006). The economics of poverty traps and persistent poverty: An assetbased approach. Journal of Development Studies, 42(2), 178-199.

Carter, M. R., \& Lybbert, T. J. (2012). Consumption versus asset smoothing: testing the implications of poverty trap theory in Burkina Faso. Journal of Development Economics, 99(2), 255-264.

Chantarat, S., Mude, A. G., Barrett, C. B. and Carter, M. R. (2013). Designing Index-Based Livestock Insurance for Managing Asset Risk in Northern Kenya. Journal of Risk and Insurance, 80, 205-237.

Chantarat, S., Mude, A. G., Barrett, C. B., \& Turvey, C. G. (2014). Welfare Impacts of Index Insurance in the Presence of a Poverty Trap. Unpublished.

Child, R. D., Heady H. F., Hickey, W. C., Peterson, R. A., \& Pieper, R. D. (Eds.). (1984). Arid and SemiArid Lands: Sustainable Use and Management in Developing Countries. Washington DC: National Park Service.

Conway, T., de Haan, A., \& Norton, A. (2000). Social protection: new directions of donor agencies. Paper for the DFID-ODI Inter-Agency Seminar on Social Protection. Easthamstead Park.

Coppock, D. L. (Ed.). (1994). The Borana Plateau of Southern Ethiopia: Synthesis of pastoral research, development, and change, 1980-91 (No. 5). ILRI (aka ILCA and ILRAD).

Covarrubias, K., Davis, B., \& Winters, P. (2012). From protection to production: productive impacts of the Malawi social cash transfer scheme. Journal of Development Effectiveness, 4(1), 50-77.

Devereux, S. (2001). Livelihood insecurity and social protection: a re-emerging issue in rural development. Development Policy Review, 19(4), 507-519.

Fafchamps, M., Udry, C., \& Czukas, K. (1998). Drought and saving in West Africa: Are livestock a buffer stock?. Journal of Development Economics, 55(2), 273-305.

Fitzgerald, J., Gottschalk, P., \& Moffitt, R. (1998). An Analysis of Sample Attrition in Panel Data: The Michigan Panel Study of Income Dynamics. Journal of Human Resources, 33(2), 251-299.

Food and Agriculture Organization of the United Nations (FAO). (2001). Pastoralism in the New Millennium. United Nations.

Food and Agriculture Organization of the United Nations (FAO). (1987). Improving Productivity of Dryland Areas. Rome.

Fiszbein, A., Schady, N. R., \& Ferreira, F. H. (2009). Conditional cash transfers: reducing present and future poverty. World Bank Publications.

G8 Summit Declaration on Freedom of Investment, Investment Environment and Social Responsibility. June 2007. 
Gertler, P. J., Martinez, S. W., \& Rubio-Codina, M. (2012). Investing cash transfers to raise long-term living standards. American Economic Journal: Applied Economics, 4(1), 164-192.

Giné, X., Townsend, R., \& Vickery, J. (2008). Patterns of rainfall insurance participation in rural India. The World Bank Economic Review, 22(3), 539-566.

Heffernan, C. (2001). Consumer preferences and the uptake of animal healthcare by the poor: a case study from Kenya. Journal of International Development, 13(7), 847-861.

Holtzman, J. S., \& Kulibaba, N. P. (1995). Livestock marketing in pastoral Africa: Policies to increase competitiveness, efficiency and flexibility. In Scoones, I. (Ed.). Living with uncertainty: New directions in pastoral development in Africa. IIED, London.

Homewood, K., Trench, P., Randall, S., Lynen, G., \& Bishop, B. (2006). Livestock health and socioeconomic impacts of a veterinary intervention in Maasailand: infection-and-treatment vaccine against East Coast fever. Agricultural Systems, 89(2), 248-271.

Hurrell, A., MacAuslan, I., \& Merttens, F. (2008). Kenya Hunger Safety Net Programme: Monitoring and evaluation strategy. Oxford Policy Management.

Hurrell, A., \& Sabates-Wheeler R. (2013). Kenya Hunger Safety Net Programme Monitoring and Evaluation Component: Quantitative Impact Evaluation Final Report: 2009 to 2012. Oxford Policy Management.

Ikegami, M., Barrett, C. \& Chantarat, S. (2012). Dynamic effects of index based livestock insurance on household intertemporal behavior and welfare. Unpublished.

International Livestock Research Institute (IRLI). (2012). Index Based Livestock Insurance for northeastern Kenya's arid and semi-arid lands: The Marsabit Pilot Project-Codebook for IBLI evaluation baseline survey. Nairobi, Kenya: ILRI.

Janzen, S. A., \& Carter, M. R. (2013). After the Drought: The Impact of Microinsurance on Consumption Smoothing and Asset Protection (No. w19702). National Bureau of Economic Research.

Jensen, N., Barrett, C., \& Mude, A. (2014). Basis Risk and the Welfare Gains from Index Insurance: Evidence from Northern Kenya. Unpublished.

Jensen N., Mude, A., \& Barrett, C. (2014) How Basis Risk and Spatiotemporal Adverse Selection Influence Demand for Index Insurance: Evidence from Northern Kenya. Unpublished.

Jensen N., Sheahana, M., Barrett, C., \& Mude, A. (2014) Hunger Safety Net Program (HSNP) and Index Based Livestock Insurance (IBLI) baseline comparison. Unpublished.

Karlan, D., Osei, R. D., Osei-Akoto, I., \& Udry, C. (2014). Agricultural decisions after relaxing credit and risk constraints. Quarterly Journal of Economics, 129 (2): 597-652.

Leblois, A., \& Quirion, P. (2010). Agricultural Insurances Based on Meteorological Indices: Realizations, Methods and Research Agenda. Fondazione Eni Enrico Mattei Working Papers. Paper 460. http://services.bepress.com/feem/paper460 
Little, P. D., McPeak, J., Barrett, C. B., \& Kristjanson, P. (2008). Challenging orthodoxies: understanding poverty in pastoral areas of East Africa. Development and Change, 39(4), 587-611.

Lybbert, T. J., Barrett, C. B., Desta, S., \& Coppock, D. (2004). Stochastic wealth dynamics and risk management among a poor population. Economic Journal, 114(498), 750-777.

Mahul, O., \& Stutley, C. J. (2010). Government support to agricultural insurance: Challenges and Options for Developing Countries. World Bank Publications.

McPeak, J. (2005). Individual and collective rationality in pastoral production: Evidence from Northern Kenya. Human Ecology, 33(2), 171-197.

McPeak, J. (2004). Contrasting income shocks with asset shocks: livestock sales in northern Kenya. Oxford Economic Papers, 56(2), 263-284.

McPeak, J., Little, P., \& Doss, C. (2011). Risk and Social Change in African Rural Economics. New York: Rutledge.

Mobarak, A., \& Rosenzweig, M. (2012). Selling formal insurance to the informally insured. Yale University Economic Growth Center Discussion Paper, (1007).

Morduch, J. (1995). Income smoothing and consumption smoothing. Journal of Economic Perspectives, 103-114.

Niamir-Fuller, M. (1999). Managing mobility in African rangelands. London: Food and Agricultural Organization and the Beijer International Institute of Ecological Economics.

Niamir-Fuller, M. (2005). Managing mobility in African rangelands. Collective Action and Property Rights for Sustainable Rangeland Management. CAPRi research brief. CAPRi.

Rosenzweig, M., and Binswanger, H. (1993) Wealth, Weather Risk and the Composition and Profitability of Agricultural Investments. Economic Journal, 103(416), 56-78.

Sahn, D. E., \& Stifel, D. C. (2000). Poverty comparisons over time and across countries in Africa. World Development, 28(12), 2123-2155.

Scoones, Ian, ed. (1994). Living with Uncertainty: New Directions in Pastoral Development in Africa. London, UK: Intermediate Technology Publications.

Sieff, D. F. (1999). The effects of wealth on livestock dynamics among the Datoga pastoralists of Tanzania. Agricultural Systems, 59(1), 1-25.

Stoeffler, Q., \& Mills, B. (2014). Households' investments in durable and productive assets in Niger: quasiexperimental evidences from a cash transfer project. Paper presented at AAEA Annual Meetings, July 27-29, 2014, Minneapolis, MN.

Toth, R. (2015). Traps and thresholds in pastoralist mobility. American Journal of Agricultural Economics. Am. J. Agr. Econ. 97 (1): 315-332

United Nations High Commissioner for Refugees (2009). Guidelines for Selective Feeding: The Management of Malnutrition in Emergencies. UNHCR: Geneva, Switzerland. Available at: http://www.unhcr.org/4b7421fd20.pdf (Accessed October 2012). 
World Health Organization. (2011). Public health risk assessment and interventions - The horn of Africa: Drought and famine crisis. Available at: http://www.who.int/diseasecontrol_emergencies/ publications/who_hse_gar_dce_2011_3.pdf?ua=1 (Accessed October 2012).

Wooldridge, J. (2002). Econometric Analysis of Cross Section and Panel Data. Cambridge, MA: MIT Press. 


\section{Figures}

Figure 1. Marsabit, Kenya: Five IBLI index divisions (Left), surveyed sublocations by HSNP and IBLI extension game status (Right)
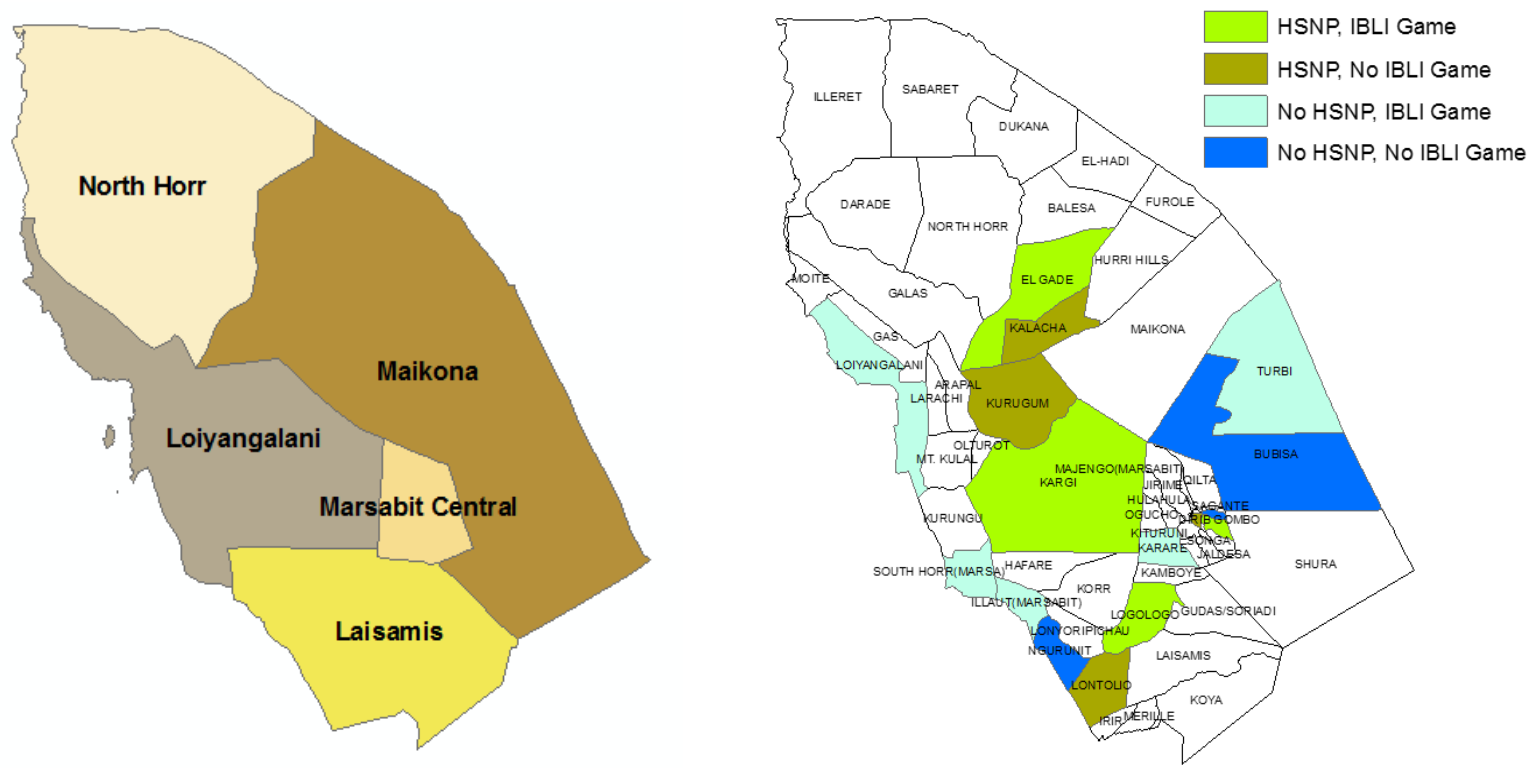

Figure 2. IBLI calendar

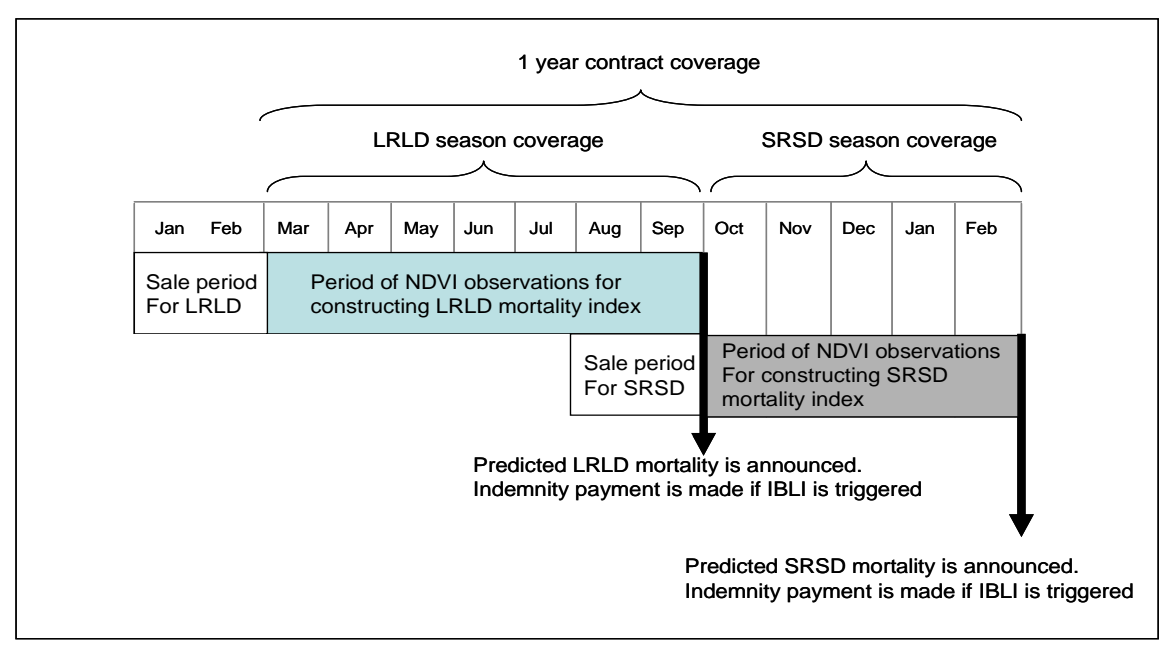


Tables

Table 1. Summary Statistics (2012)

\begin{tabular}{|c|c|c|c|c|c|}
\hline & Observations & Mean & Standard Deviation & Min & Max \\
\hline \multicolumn{6}{|l|}{ Household Attributes: } \\
\hline Male & 838 & 0.592 & 0.486 & 0 & 1 \\
\hline Age of Head & 838 & 48.0 & 16.3 & 21 & 99 \\
\hline Head is Widow & 838 & 0.141 & 0.347 & 0 & 1 \\
\hline Education & 838 & 3.97 & 4.50 & 0 & 15 \\
\hline Adult Equivalent & 838 & 4.99 & 2.09 & 0.7 & 14.6 \\
\hline Dependency Ratio & 838 & 0.617 & 0.180 & 0 & 1 \\
\hline Max Age & 838 & 50.3 & 16.3 & 21 & 100 \\
\hline Community Based Need & 838 & 0.765 & 0.243 & 0 & 0.993 \\
\hline Herd Size & 838 & 10.9 & 16.0 & 0 & 194 \\
\hline Vet Expenditures on livestock & 838 & 563 & 730 & 0 & 7,500 \\
\hline Vet Expenditures on livestock/TLU & 797 & 86.8 & 159 & 0 & 1,690 \\
\hline Vet Expenditures on livestock/TLU $\mid>0$ & 577 & 112 & 178 & 2.40 & 1,690 \\
\hline Ratio livestock held at home & 838 & 0.256 & 0.375 & 0 & 1 \\
\hline Mobile & 838 & 0.614 & 0.498 & 0 & 1 \\
\hline Income from Milk & 838 & 5,800 & 9,180 & 0 & 13,300 \\
\hline Milk Income per TLU & 798 & 548 & 762 & 0 & 8,890 \\
\hline Milk Income per TLU $\mid>0$ & 735 & 602 & 776 & 8.35 & 8,890 \\
\hline TLU losses & 838 & 0.944 & 2.50 & 0 & 31.7 \\
\hline Livestock Mortality Rate & 798 & 0.0868 & 0.148 & 0 & 1 \\
\hline Livestock Sales & 495 & 1.03 & 1.44 & 0.1 & 17.3 \\
\hline Consumption per AE & 838 & 1,490 & 2,060 & 228 & 51,500 \\
\hline Asset Index & 838 & 0.095 & 0.992 & -0.864 & 7.57 \\
\hline Income & 838 & 10,200 & 13,100 & 0 & 170,000 \\
\hline Ratio Food from Aid & 838 & 0.263 & 0.156 & 0 & 0.824 \\
\hline School Absenteeism & 563 & 0.537 & 3.10 & 0 & 30.000 \\
\hline School Enrollment & 674 & 0.552 & 0.396 & 0 & 1 \\
\hline \multicolumn{6}{|l|}{ Child Attributes: } \\
\hline Male & 478 & 0.491 & 0.500 & 0 & 1 \\
\hline Age (months) & 478 & 34.0 & 15.1 & 6 & 60 \\
\hline Supplementary Food & 454 & 0.104 & 0.313 & 0 & 1 \\
\hline MUAC & 431 & -0.561 & 1.688 & -4 & 4 \\
\hline \multicolumn{6}{|l|}{ Program Variables: ${ }^{\mathrm{A}}$} \\
\hline HSNP Participant (HSNP) & 838 & 0.363 & 0.483 & 0 & 1 \\
\hline Cumulative HSNP (HSNPC) & 838 & 1.60 & 2.32 & 0 & 6 \\
\hline IBLI Coverage (IBLI) & 838 & 0.254 & 1.32 & 0 & 22 \\
\hline Cumulative IBLI (IBLIC) & 838 & 0.543 & 0.743 & 0 & 3 \\
\hline \multicolumn{6}{|l|}{ Program Variables: ${ }^{\mathrm{B}}$} \\
\hline HSNP Participant (HSNP) & 367 & 0.855 & 0.360 & 0 & 1 \\
\hline Cumulative HSNP (HSNPC) & 367 & 3.76 & 1.76 & 0 & 6 \\
\hline IBLI Coverage (IBLI) & 352 & 0.599 & 1.94 & 0 & 22 \\
\hline Cumulative IBLI (IBLIC) & 352 & 1.26 & 0.556 & 1 & 3 \\
\hline
\end{tabular}

See Table A1 for a description of each variable. ${ }^{\text {A }}$ Summary statistics for all households. ${ }^{\text {B }}$ Summary statistics of those households that have ever participated in each respective program. 
Table 2. Rollout of HNSP across IBLI survey households in 2009-2012 survey rounds

\begin{tabular}{lrrrr}
\hline & \multicolumn{4}{c}{ Survey Year } \\
& 2009 & 2010 & 2011 & 2012 \\
\hline Non-participants & 678 & 574 & 503 & 524 \\
$1^{\text {st }}$ year of participation & 154 & 120 & 80 & 10 \\
$2^{\text {nd }}$ year of participation & 0 & 138 & 113 & 62 \\
$3^{\text {rd }}$ year of participation & 0 & 0 & 133 & 106 \\
$4^{\text {th }}$ year of participation & 0 & 0 & 0 & 130 \\
Total $^{1}$ & 832 & 832 & 829 & 832 \\
\hline A balanced panel is used for Table $2 .{ }^{1}$ Changes to total are due to missing \\
participation data.
\end{tabular}

Table 3. IBLI uptake and demand conditional on purchase in the IBLI survey, Jan. 2010 - Nov. 2012

\begin{tabular}{|c|c|c|c|c|c|c|c|c|}
\hline \multirow{3}{*}{$\frac{\text { Year }}{2010}$} & \multirow{3}{*}{$\frac{\text { Season }}{\text { LRLD }}$} & \multirow{2}{*}{$\begin{array}{c}\text { Purchasing } \\
\text { Households (N) }\end{array}$} & \multicolumn{6}{|c|}{ Average purchased coverage (standard deviation) } \\
\hline & & & Marsabit Central & Laisamis & \multicolumn{2}{|c|}{ Loiyangalani } & \multicolumn{2}{|c|}{ Maikona } \\
\hline & & 256 & $6.58(7.65)$ & $3.37(4.65)$ & 2.34 & (2.19) & 2.75 & $(2.57)$ \\
\hline & SRSD & - & & & & & & \\
\hline \multirow[t]{2}{*}{2011} & LRLD & 134 & (2.93) & (3.98) & 2.30 & (2.79) & 4.15 & (3.77) \\
\hline & SRSD & 127 & (3.06) & (1.48) & 1.92 & (1.53) & 4.18 & $(5.55)$ \\
\hline \multirow[t]{2}{*}{2012} & LRLD & - & & & & & & \\
\hline & SRSD & 80 & (3.57) & $(0.87)$ & 1.50 & $(0.95)$ & 3.49 & $(6.27)$ \\
\hline
\end{tabular}

The total number of surveyed household in each round was 924. LRLD is the long rain/long dry season that lasts from March $1^{\text {st }}$ through September $30^{\text {th }}$. SRSD is the short rain/short dry season that lasts from October $1^{\text {st }}$ through then end of February.

Table 4. Index values and associated indemnity rates

\begin{tabular}{lcccc}
\hline & \multicolumn{3}{c}{ Index = predicted mortality rate (indemnity rate) } & \\
\cline { 3 - 4 } Season & Marsabit Central & Laisamis & Loiyangalani & Maikona \\
\hline LRLD 2010 & $0.00(0)$ & $0.02(0)$ & $0.02(0)$ & $0.01(0)$ \\
SRSD 2010 & $0.06(0)$ & $0.06(0)$ & $0.06(0)$ & $0.02(0)$ \\
LRLD 2011 & $0.26(0.11)$ & $0.22(0.07)$ & $0.18(0.03)$ & $0.33(0.18)$ \\
SRSD 2011 & $0.23(0.08)$ & $0.20(0.05)$ & $0.12(0)$ & $0.06(0)$ \\
LRLD 2012 & $0.05(0)$ & $0.02(0)$ & $0.03(0)$ & $0.02(0)$ \\
\hline
\end{tabular}

LRLD is the long rain/long dry season that lasts from March $1^{\text {st }}$ through September $30^{\text {th }}$. SRSD is the short rain/short dry season that lasts from October $1^{\text {st }}$ through February $28^{\text {th }}$. 
Table 5. The impact of covariate shocks, HSNP participation, and IBLI coverage on livestock sales (TLUs)

\section{Current HSNP Participation $\quad$ Current IBLI Coverage (TLU)}

\begin{tabular}{lcc}
\hline Shock & $0.270^{* * *}$ & $0.377^{* * *}$ \\
& $(0.074)$ & $(0.113)$ \\
Participation/Coverage (P/C) & 0.165 & $0.226^{* * *}$ \\
& $(0.157)$ & $(0.085)$ \\
P/C*Shock & -0.076 & $-0.256^{*}$ \\
& $(0.177)$ & $(0.144)$ \\
& & \\
$\mathrm{H}_{0}:$ P/C + P/C *Shock=0 & {$[0.426]$} & {$[-0.268]$} \\
[z-score] & & \\
Observations & 6,551 & 6,557 \\
Households & 895 & 895 \\
Model F-statistic & 4.932 & 5.236 \\
\hline
\end{tabular}

The shock is an indicator that the division average livestock mortality rates in the current season are equal to or above $15 \%$. Both models include the following covariates: adult equivalence, age of head, age of head squared, maximum education in household, a dummy indicating the head of household is a widow, the current season's predicted livestock mortality rate, the current season's predicted livestock mortality rate squared, division-period dummies and the three HSNP targeting characteristics to the first, second, and third power. Clustered robust standard errors in parentheses. *** $\mathrm{p}<0.01,{ }^{* *} \mathrm{p}<0.05$, * $\mathrm{p}<0.1$. 
Table 6. Impact of HSNP participation and IBLI coverage on production strategies and outcomes

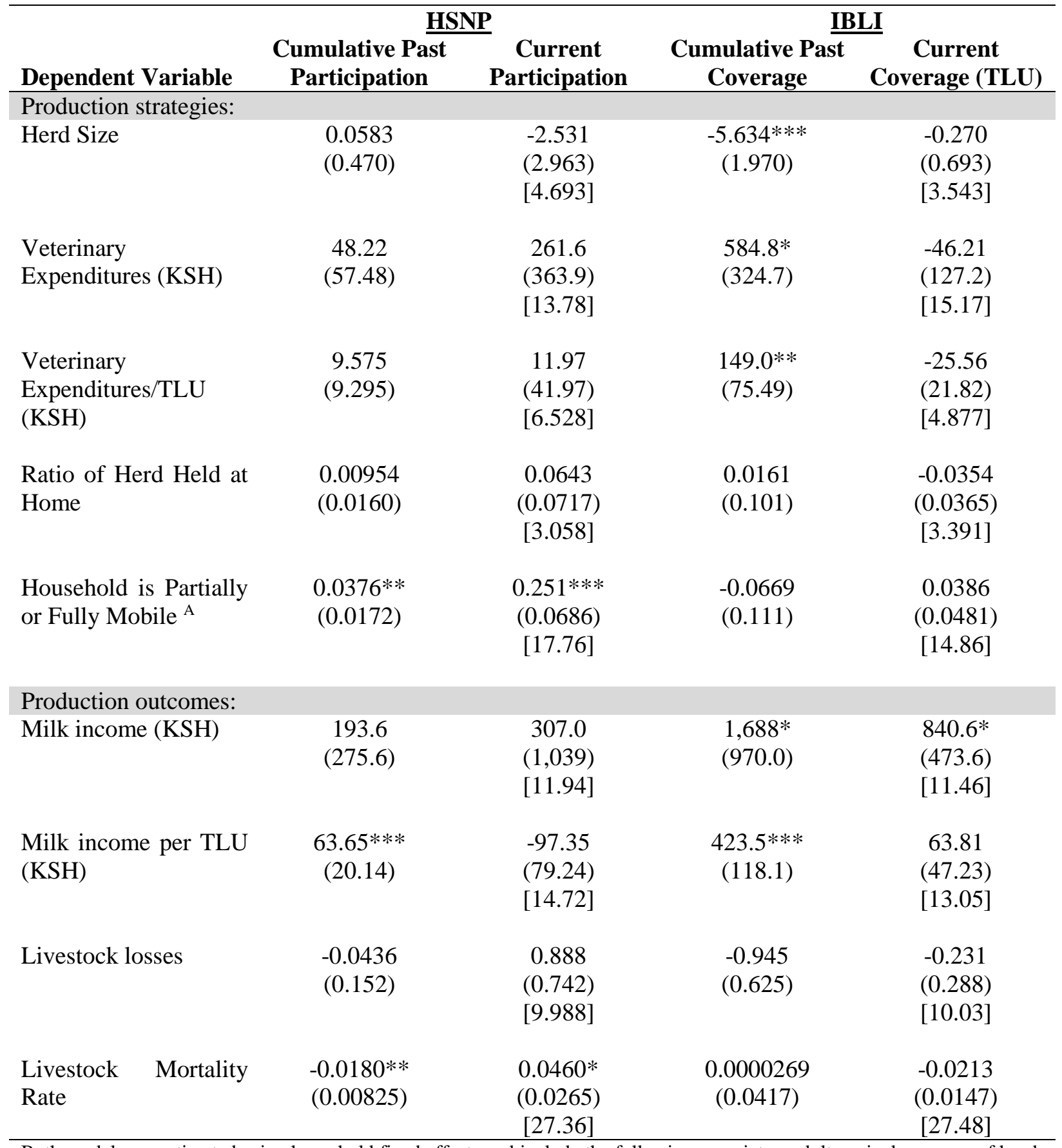

Both models are estimated using household fixed effects and include the following covariates: adult equivalence, age of head, age of head squared, maximum education in household, a dummy indicating the head of household is a widow, the current season's predicted livestock mortality rate, the current season's predicted livestock mortality rate squared, division-period dummies and the three HSNP targeting characteristics to the first, second, and third power. ${ }^{\mathrm{A}} \mathrm{A}$ linear probability model is used to estimate the likelihood that a household is partially or fully mobile. Clustered and robust standard errors in parentheses. Model F-statistics in brackets. $* * * \mathrm{p}<0.01, * * \mathrm{p}<0.05, * \mathrm{p}<0.1$. 
Table 7. Impact of HSNP participation and IBLI coverage on household welfare

\begin{tabular}{|c|c|c|c|c|}
\hline \multirow[b]{2}{*}{ Dependent Variable } & \multicolumn{2}{|c|}{$\underline{\text { HSNP }}$} & \multicolumn{2}{|c|}{$\underline{\text { IBLI }}$} \\
\hline & $\begin{array}{l}\text { Cumulative Past } \\
\text { Participation }\end{array}$ & $\begin{array}{c}\text { Current } \\
\text { Participation }\end{array}$ & $\begin{array}{c}\text { Cumulative } \\
\text { Past Coverage }\end{array}$ & $\begin{array}{c}\text { Current } \\
\text { Coverage } \\
\text { (TLU) }\end{array}$ \\
\hline Consumption per $\mathrm{AE}$ & $\begin{array}{l}-56.09 * \\
(32.22)\end{array}$ & $\begin{array}{l}-391.0 \\
(249.9) \\
{[16.63]}\end{array}$ & $\begin{array}{l}-141.1 \\
(245.2)\end{array}$ & $\begin{array}{c}75.46 \\
(90.65) \\
{[15.45]}\end{array}$ \\
\hline Asset Index & $\begin{array}{c}-7.550 * * * \\
(2.513)\end{array}$ & $\begin{array}{c}5.596 \\
(8.184) \\
{[21.96]}\end{array}$ & $\begin{array}{l}-14.53 \\
(17.86)\end{array}$ & $\begin{array}{l}-6.095 \\
(4.509) \\
{[21.55]}\end{array}$ \\
\hline Income per $\mathrm{AE}$ & $\begin{array}{c}43.42 \\
(38.04)\end{array}$ & $\begin{array}{l}268.3 \\
(233.2) \\
{[20.36]}\end{array}$ & $\begin{array}{c}72.73 \\
(241.9)\end{array}$ & $\begin{array}{c}285.2 * * \\
(121.8) \\
{[21.61]}\end{array}$ \\
\hline School Absenteeism & $\begin{array}{l}-0.207 \\
(0.204)\end{array}$ & $\begin{array}{l}-0.269 \\
(1.618) \\
{[2.157]}\end{array}$ & $\begin{array}{c}0.249 \\
(1.601)\end{array}$ & $\begin{array}{c}0.804 \\
(0.647) \\
{[2.300]}\end{array}$ \\
\hline School Enrollment & $\begin{array}{c}0.0238 \\
(0.0172)\end{array}$ & $\begin{array}{c}-0.00421 \\
(0.0691) \\
{[1.833]}\end{array}$ & $\begin{array}{c}0.101 \\
(0.0827)\end{array}$ & $\begin{array}{c}0.0320 \\
(0.0293) \\
{[2.083]}\end{array}$ \\
\hline MUAC & $\begin{array}{c}0.0484 \\
(0.0953)\end{array}$ & $\begin{array}{c}1.017 * * \\
(0.492) \\
{[3.440]}\end{array}$ & $\begin{array}{c}0.753 \\
(0.770)\end{array}$ & $\begin{array}{c}0.0588 \\
(0.205) \\
{[2.945]}\end{array}$ \\
\hline $\operatorname{Pr}(\mathrm{MUAC} \leq 12.5 \mathrm{~cm})$ & $\begin{array}{c}-0.0577 * \\
(0.0301)\end{array}$ & $\begin{array}{c}-0.370 * * * \\
(0.141) \\
{[1.738]}\end{array}$ & $\begin{array}{l}-0.282 \\
(0.211)\end{array}$ & $\begin{array}{c}0.0684 \\
(0.0528) \\
{[1.496]}\end{array}$ \\
\hline
\end{tabular}

Both models include the following covariates: adult equivalence, age of head, age of head squared, maximum education in household, a dummy indicating the head of household is a widow, the current season's predicted livestock mortality rate, the current season's predicted livestock mortality rate squared, division-period dummies and the three HSNP targeting characteristics to the first, second, and third power. Clustered robust standard errors in parentheses. Model F-statistic in brackets. $* * * \mathrm{p}<0.01$, $* * \mathrm{p}<0.05, * \mathrm{p}<0.1$. 
Table 8. The impact of accumulated HSNP transfers and IBLI coverage on household welfare

\begin{tabular}{|c|c|c|c|}
\hline Dependent Variable & $\begin{array}{c}\text { Accumulated HSNP } \\
\text { Seasons }\end{array}$ & $\begin{array}{c}\text { Accumulated IBLI Coverage } \\
\text { Seasons }\end{array}$ & Interaction \\
\hline Consumption per $\mathrm{AE}$ & $\begin{array}{c}-136.2 * * \\
(63.90)\end{array}$ & $\begin{array}{c}197.7 \\
(218.7)\end{array}$ & $\begin{array}{c}86.99 \\
(75.71) \\
{[14.23]}\end{array}$ \\
\hline Asset Index & $\begin{array}{l}-0.0686^{* *} \\
(0.0289)\end{array}$ & $\begin{array}{l}-0.108 \\
(0.135)\end{array}$ & $\begin{array}{c}0.00378 \\
(0.0366) \\
{[20.01]}\end{array}$ \\
\hline Income per $\mathrm{AE}$ & $\begin{array}{l}98.95 \\
(69.74)\end{array}$ & $\begin{array}{l}29.63 \\
(259.8)\end{array}$ & $\begin{array}{l}-59.98 \\
(93.68) \\
{[19.50]}\end{array}$ \\
\hline School Absenteeism & $\begin{array}{l}-0.187 \\
(0.423)\end{array}$ & $\begin{array}{c}1.682 \\
(1.615)\end{array}$ & $\begin{array}{l}-0.105 \\
(0.539) \\
{[2.410]}\end{array}$ \\
\hline School Enrollment & $\begin{array}{l}0.0443 * \\
(0.0235)\end{array}$ & $\begin{array}{c}0.113 \\
(0.0788)\end{array}$ & $\begin{array}{c}-0.0400 * \\
(0.0230) \\
{[1.679]}\end{array}$ \\
\hline MUAC & $\begin{array}{c}0.700^{* *} \\
(0.309)\end{array}$ & $\begin{array}{l}1.662^{* *} \\
(0.837)\end{array}$ & $\begin{array}{l}-0.759 \\
(0.473) \\
{[3.308]}\end{array}$ \\
\hline $\operatorname{Pr}(\mathrm{MUAC} \leq 12.5 \mathrm{~cm})$ & $\begin{array}{l}-0.128 * * \\
(0.0641)\end{array}$ & $\begin{array}{l}-0.117 \\
(0.140)\end{array}$ & $\begin{array}{c}0.115 \\
(0.117) \\
{[1.334]}\end{array}$ \\
\hline
\end{tabular}

Both models include the following covariates: adult equivalence, age of head, age of head squared, maximum education in household, a dummy indicating the head of household is a widow, the current season's predicted livestock mortality rate, the current season's predicted livestock mortality rate squared, division-period dummies and the three HSNP targeting characteristics to the first, second, and third power. Clustered robust standard errors in parentheses. $* * * \mathrm{p}<0.01,{ }^{*} \mathrm{p}<0.05, * \mathrm{p}<0.1$. 
Table 9. Average value of each program variable during the final period of analysis among program clients

\begin{tabular}{|c|c|}
\hline VOI & Mean VOI in Final Period \\
\hline $\mathrm{HSNP}^{\mathrm{A}}$ & 0.86 \\
\hline HSNPC $^{B}$ & 3.76 \\
\hline IBLI $^{\mathrm{C}}$ & 0.60 \\
\hline IBLIC $^{\mathrm{D}}$ & 1.26 \\
\hline \multicolumn{2}{|c|}{$\begin{array}{l}\text { To determine the final impact of each program, we estimate the average values of each program } \\
\text { variable in the final period and in each case, restricting the sample to those that had ever been a } \\
\text { client of that program. }{ }^{\mathrm{A}} \text { HSNP is equal to one if the household is an HSNP participant in the } \\
\text { final season. }{ }^{\mathrm{B}} \mathrm{HSNPC} \text { is the lagged average cumulative seasons as an HSNP participant by the } \\
\text { final season. }{ }^{\mathrm{C}} \text { IBLI is equal to the amount of coverage in TLUs during the final season. }{ }^{\mathrm{D}} \text { IBLIC } \\
\text { is equal to the number of preceding seasons with IBLI coverage during the final season. }\end{array}$} \\
\hline
\end{tabular}

Table 10. Average benefits per unit cost by the final survey season

\begin{tabular}{|c|c|c|c|c|c|c|c|}
\hline \multirow[b]{2}{*}{ Cost structure } & \multirow[b]{2}{*}{ Cost } & \multicolumn{2}{|c|}{ Income from Milk } & \multicolumn{2}{|c|}{ Income per $\mathrm{AE}$} & \multicolumn{2}{|c|}{ MUAC } \\
\hline & & Impact & Impact/KSH & Impact & $\begin{array}{c}\text { Impact/ } \\
\mathrm{KSH}^{1}\end{array}$ & Impact & Impact/KSH ${ }^{2}$ \\
\hline Program HSNP & 47,600 & 992 & 0.021 & 394 & 0.083 & 1.097 & 0.022 \\
\hline Cost/Participant IBLI & 37,600 & 2,631 & 0.067 & 263 & 0.070 & 0.337 & 0.026 \\
\hline Marginal Cost of an HSNP & 31,700 & 992 & 0.031 & 394 & 0.124 & 1.097 & 0.033 \\
\hline Additional Participant IBLI & 1,580 & 2,631 & 1.667 & 263 & 1.666 & 0.337 & 0.623 \\
\hline
\end{tabular}

All values in real 2009 Kenya Shillings. Costs estimates are described in section 4. Impacts are estimated using the average values provided in Table 9 and parameter estimates in Table 6 and Table 7. ${ }^{1}$ Results are multiplied by 10. ${ }^{2}$ Results are multiplied by 1,000 . 


\section{INDEX INSURANCE AND CASH TRANSFERS: A COMPARATIVE ANALYSIS FROM NORTHERN KENYA}

-ONLINE APPENDIX-

December 2014

Nathaniel D. Jensen

Cornell University

Christopher B. Barrett

Cornell University

Andrew G. Mude

International Livestock Research Institute

\section{Contents:}

Appendix A: Variable Construction and Attrition

Appendix B: HSNP Adherence to Selection and Precision of Targeting

Appendix C: HSNP Instruments

Appendix D: IBLI Instruments

Appendix E: Further Analysis of Households' Responses to Shocks

Appendix F: Pooled Instrumental Variables Estimates

Appendix G: Heterogeneity in Average Program Effects

\section{Corresponding author:}

Nathaniel Jensen, 340J Warren Hall, Cornell University, Ithaca, NY 14850.

Email: ndj6@cornell.edu 


\section{Appendix A: Variable Construction and Attrition}

\section{Variable Construction}

This research uses data from the IBLI household survey. Except for the case of the child variables, all of the variables are constructed at the household level. The collection process was annual but included month and season specific questions for characteristics that were likely to vary significantly over time. In cases where monthly or seasonal data were collected, we construct season specific values. Table A1 provides a description of how the variables were constructed from the survey data.

Table A1. Description of key variables

\begin{tabular}{|c|c|}
\hline \multicolumn{2}{|c|}{ Household Attributes: } \\
\hline Male & $=1$ if head of household is male. \\
\hline Age of Head & Age of head of household, in years. \\
\hline Head is Widow & $=1$ if head of household is a widow. \\
\hline Education & $\begin{array}{l}\text { Maximum education achieved by a household member, in years. } 1-8 \text { are standards, 9- } \\
12 \text { are forms } 1-4 \text {, diploma is } 13 \text {, degree is } 14 \text {, and postgraduate is } 15 \text {. }\end{array}$ \\
\hline Adult Equivalent & $\begin{array}{l}\text { The sum of household members' adult equivalence (AE) where } \mathrm{AE} \text { is determined by } \\
\text { the following: } \mathrm{AE}=0.5 \text { if age }<5, \mathrm{AE}=0.7 \text { if } 4<\text { age }<16 \text { or age }>60, \mathrm{AE}=1 \text { if } 15<\text { age }<61 \text {. }\end{array}$ \\
\hline $\begin{array}{l}\text { Dependency } \\
\text { Ratio }\end{array}$ & $\begin{array}{l}\text { The ratio of dependents to total household members. For consistency with the HSNP } \\
\text { targeting criteria, we us the definition of dependents as those members that are under } \\
18 \text { or over } 55 \text { years old, chronically ill or have a disability (Hurrell \& Sabates-Wheeler } \\
2013 \text { ). }\end{array}$ \\
\hline Max Age & Age of oldest household member, in years \\
\hline $\begin{array}{l}\text { Community } \\
\text { Based Need }\end{array}$ & $\begin{array}{l}\text { The likelihood of HSNP participation generated using parameters estimated by } \\
\text { regressing HSNP participation on a set of covariates for households in communities } \\
\text { that used community based targeting, as described in Appendix B. The covariates } \\
\text { used in that regression are described below. }\end{array}$ \\
\hline Herd Size & $\begin{array}{l}\text { Sum of livestock owned by the households where } 1 \mathrm{TLU}=0.7 \text { camels }=1 \text { cattle }=10 \\
\text { sheep }=10 \text { goats. }\end{array}$ \\
\hline $\begin{array}{l}\text { Vet Expenditures } \\
\text { on livestock }\end{array}$ & $\begin{array}{l}\text { Total amount spend on vaccinations and other veterinary services in the last } 12 \\
\text { months in real (February 2009) Kenya Shillings. }\end{array}$ \\
\hline $\begin{array}{l}\text { Ratio livestock } \\
\text { held at home }\end{array}$ & $\begin{array}{l}\text { The ratio of livestock that the household never moved to satellite camps in the last } 12 \\
\text { months as a proportion of total herd size. }\end{array}$ \\
\hline Mobile & $\begin{array}{l}\text { A set of three mutually exclusive dummy variables indicating that the household is } \\
\text { fully settled, partially settled, or nomadic. }\end{array}$ \\
\hline $\begin{array}{l}\text { Income from } \\
\text { Milk }\end{array}$ & $\begin{array}{l}\text { Value of seasonal average monthly milk production in real (February 2009) Kenya } \\
\text { Shillings. }{ }^{\text {. }}\end{array}$ \\
\hline TLU losses & Total number of livestock that died in that season (TLU). \\
\hline $\begin{array}{l}\text { Livestock } \\
\text { Mortality Rate }\end{array}$ & $\begin{array}{l}\text { Total number of livestock that died in that season divided by the total number of } \\
\text { livestock owned in that season. }\end{array}$ \\
\hline Livestock Sales & Livestock sold (TLU). \\
\hline $\begin{array}{l}\text { Consumption per } \\
\mathrm{AE}\end{array}$ & $\begin{array}{l}\text { Value of monthly consumption per adult equivalent estimated using weekly recall of } \\
\text { food purchases, one month recall of less frequent consumables purchases (e.g., } \\
\text { charcoal, soap, transportation), three month recall of recreation and health related } \\
\text { expenses, and } 12 \text { month recall of large purchases and durables (e.g., cloths, school } \\
\text { fees, kitchen equipment). See the survey codebook for more details (IRLI 2012). }{ }^{2}\end{array}$ \\
\hline
\end{tabular}

Table Al continues. 
Table Al continued.

\begin{tabular}{|c|c|}
\hline Asset Index & $\begin{array}{l}\text { The asset index is generated using a factor analysis of household productive assets } \\
\text { and other durables, primary cooking and lighting fuels, household construction } \\
\text { materials, primary water source, and toilet facilities. The details of the factor analysis } \\
\text { are found next and in Table A2. }\end{array}$ \\
\hline Income & Average monthly income in real (February 2009) Kenya Shillings. \\
\hline $\begin{array}{l}\text { Ratio Food from } \\
\text { Aid }\end{array}$ & Total food aid as a share of total food consumption including food aid. \\
\hline $\begin{array}{l}\text { School } \\
\text { Absenteeism }\end{array}$ & Number of days in the past 12 months that an enrolled student missed from school. \\
\hline $\begin{array}{l}\text { School } \\
\text { Enrollment }\end{array}$ & Ratio of school aged children (ages 6-18) enrolled in school. \\
\hline \multicolumn{2}{|l|}{ Child Attributes: } \\
\hline Male & $=1$ if child is a male. \\
\hline Age & Age of child in months. \\
\hline $\begin{array}{l}\text { Supplementary } \\
\text { Food }\end{array}$ & $=1$ if child is receiving supplementary food. \\
\hline MUAC & Survey measured mid-upper arm circumference. \\
\hline \multicolumn{2}{|c|}{ Additional variables used to estimate community based HSNP eligibility. } \\
\hline Aid & $\begin{array}{l}\text { Average seasonal value of monthly food aid and employment programs from NGOs } \\
\text { or the government in real (February 2009) Kenya Shillings. }\end{array}$ \\
\hline CID & $=1$ if household has member that is chronically ill or disabled. \\
\hline Savings & $=1$ if household has savings \\
\hline \multicolumn{2}{|c|}{ IBLI Control Variables } \\
\hline Index & $\begin{array}{l}\text { Season's predicted livestock mortality rate based on the IBLI response function } \\
\text { (index). }\end{array}$ \\
\hline Coupon & $=$ percent discount provided by the randomly distributed coupons. \\
\hline \multicolumn{2}{|c|}{ Program Variables } \\
\hline HSNP & $=1$ if household is an HSNP participant in the current season. \\
\hline HSNPC & The total number of preceding seasons as an HSNP participant. \\
\hline IBLI & Amount of current coverage in TLUs. \\
\hline IBLIC & The cumulative preceding seasons with IBLI coverage. \\
\hline
\end{tabular}

Notes: ${ }^{1}$ Milk is valued at the median seasonal price for each animal. 2The value of consumption was estimated using the seasonal within community median reported prices for each food type and quantity. When there were fewer than 5 food type-quantity observations at the community level, large administrative divisions were used.

The asset index is constructed using the factor loadings from a factor analysis on a set of household assets and construction materials similar to the process described in Sahn and Stifle (2000). The assets groups and their first factor loadings, which used to calculate each household's asset index, are found in Table A2. 
Table A2. Variables and their factor loadings used to construct the asset index

\begin{tabular}{|c|c|c|}
\hline Variable & Description & $\begin{array}{l}\text { Factor } \\
\text { Loading }\end{array}$ \\
\hline Walls & $\begin{array}{l}=1 \text { if walls are stone, brick, cement, corrugated iron or tin. }=0 \text { if walls are } \\
\text { mud, wood, grass, sticks, leaves or constructed of various materials. }\end{array}$ & 0.157 \\
\hline Floor & $=1$ if the floor is cement, tile or wood. $=0$ if floor is mud, sand or natural. & 0.148 \\
\hline Toilet & $\begin{array}{l}=1 \text { if facilities are flush or covered latrine (vented \& unvented). }=0 \text { if } \\
\text { facilities are uncovered pit latrine or none. }\end{array}$ & 0.111 \\
\hline Light & $\begin{array}{l}=1 \text { if main source of lighting is electricity, paraffin, gas, or solar. =0 if main } \\
\text { source of lighting is flashlight, wood, candle or biomass residue. }\end{array}$ & 0.110 \\
\hline Cook & $\begin{array}{l}=1 \text { if main cooking appliance is jiko, stove, gas cooker, or electric cooker. } \\
=0 \text { if main cooking is done on a traditional fire. }\end{array}$ & 0.071 \\
\hline Fuel & $\begin{array}{l}=1 \text { if the main cooking fuel is electricity, gas, paraffin, or charcoal. }=0 \text { if } \\
\text { main fuel is wood. }\end{array}$ & 0.053 \\
\hline Furniture & $\begin{array}{l}\text { Total number of the following assets: metal trunks, mosquito nets, modern } \\
\text { chairs, modern tables, wardrobes, mattresses and modern beds. }\end{array}$ & 0.191 \\
\hline Open & $=1$ if households' main water supply is open and unprotected & 0.005 \\
\hline Protected Well & $=1$ if households' main water supply is a protected well & 0.006 \\
\hline Borehole & $=1$ if households' main water supply is a borehole & -0.006 \\
\hline Tap & $=1$ if households' main water supply is a tap & 0.035 \\
\hline Rain & $=1$ if households' main water supply is rain & 0.038 \\
\hline Water Tanker & $=1$ if households' main water supply is from a water tanker & 0.005 \\
\hline Education & Maximum level of education in the household. & 0.072 \\
\hline Cash & Cash holdings on-hand or held in a savings. & 0.045 \\
\hline Land & Hectares of land owed. & 0.022 \\
\hline Irrigation & Hectare of land irrigated. & 0.017 \\
\hline Poultry & Number of poultry owned. & 0.039 \\
\hline Donkeys & Number of donkeys owned. & 0.003 \\
\hline Very small & $\begin{array}{l}\text { Total number of the following assets: gourds, cups, scissors, and needle and } \\
\text { thread sets. }\end{array}$ & 0.029 \\
\hline Small tools & $\begin{array}{l}\text { Total number of the following assets: anvils, panier, sickle, pickaxe, hoe, } \\
\text { spade, machetes, spears, bows, club, chisels, hammers, files, fishing lines. }\end{array}$ & 0.109 \\
\hline Small other & $\begin{array}{l}\text { Total number of the following assets: musical instruments, traditional tools, } \\
\text { bells, knifes, basins, sufirias, thermoses, buckets, wristwatches, jewelry }\end{array}$ & 0.023 \\
\hline Medium tools & $\begin{array}{l}\text { Total number of the following assets: Wheelbarrows, fishing nets, mobile } \\
\text { phones, washing machines, spinning machines, weaving machines, sewing } \\
\text { machines, bicycles, and plows. }\end{array}$ & 0.219 \\
\hline Medium other & $\begin{array}{l}\text { Total number of the following assets: water tank, jerry can, paraffin lamp, } \\
\text { water drum, kerosene stove, charcoal stoves, ovens and radios. }\end{array}$ & 0.146 \\
\hline Large & Total number of the following assets: animal carts, shops, stalls and boats. & 0.015 \\
\hline Large with motor & Total number of the following assets: cars, motorbikes and tractors. & 0.045 \\
\hline
\end{tabular}

\section{Analysis of Attrition}

A total of 924 households were surveyed in each round with attrition rates less than $4 \%$ between rounds. All exited households were replaced so that the sample size is 924 in all rounds. Whenever possible, exited households were replaced with households in the same community and wealth stratum. In some cases that 
was not possible due to availability constraints. In those cases, a household from a neighboring wealth stratum was chosen.

We use 2009 data to compare the attrited households with the balanced panel. Those households that leave the survey have more educated household heads, smaller families, spend more on livestock, keep a smaller portion of their livestock at home, suffer fewer livestock losses, consumer more per AE, but have less income and depend less on food aid, and have children that miss fewer days of school.

Table A3. Summary statistics of the balanced panel and those that left the survey

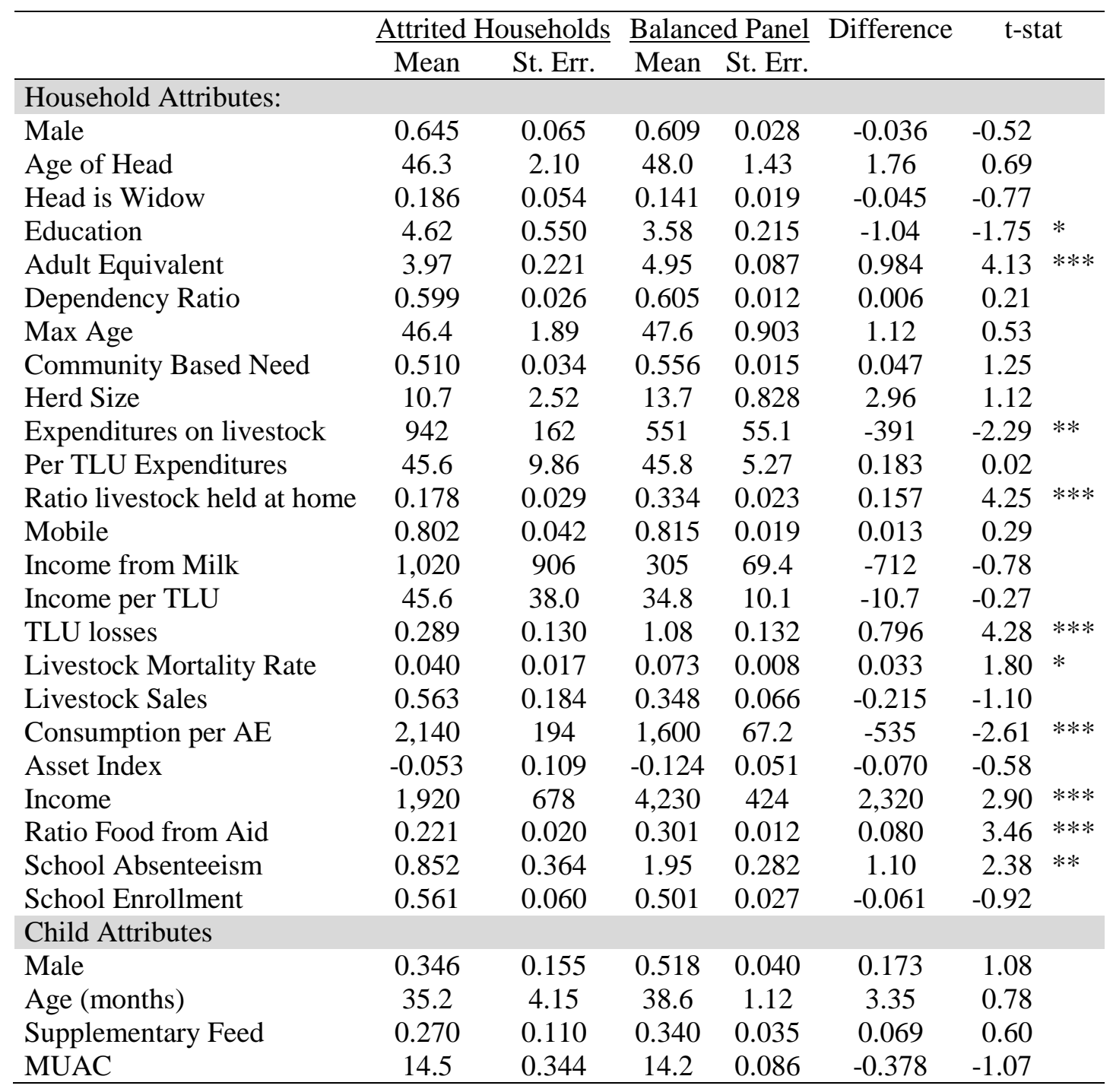

Although 4\% is an extremely low rate of attrition, the differences between the balanced panel and attrited households do raise a concern that our main analysis could suffer from attrition bias. As an initial test for attrition bias, we estimated the main estimates found in Table 6 and Table 7 of this paper with the balanced and unbalanced panels. Comparing those estimates found statistically significant changes in parameters of interest in about $15 \%$ of the cases. In response, we adjust our analysis for attrition using the inverse probability weights method developed by Fitzgerald, Gottschalk and Moffitt (1988). The basic idea is to re-weight observations so as to place more importance on those households that are similar to households 
that leave the survey. This approach assumes that attrition can, at least partially, be associated with certain observed characteristics.

The weights are generated by regressing survey participation onto a set of observables using a probit model, which is then used to predict participation. The procedure is then repeated with a subset of those variables included in the first iteration. The excluded variables in the second or "restricted" regression should affect the propensity of attrition and are presumed related to the density of the outcome variables of interest. Generally, the excluded variables are variables that the researcher believes impacts both attrition and outcomes, but would not normally be included in the outcome analysis. Common examples include lagged outcome variables, village level attrition rates, and indicators of exogenous shocks.

Following Wooldridge (2002), we only include the households that are present in the first survey round, omitting households that enter the survey after the first round altogether. Probit analyses are performed for each survey round by regressing households' survey participation status on baseline characteristics: age, education level of the head, widow status of the head, household dependency ratio, adult equivalence and household mobility status. In addition, the first unrestricted regression includes village level attrition, previous season's sublocation average loss rate, and the households' ethnic group. The model statistics for these analysis show that attrition is associated with household characteristics and that the excluded variables do improve the model's fit (Table A4).

Table A4. Full and restricted probit regressions used to construct inverse weights

\begin{tabular}{llcc}
\hline Survey Round & Model Statistic & Unrestricted Probit & Restricted Probit \\
\hline 2 & Wald $\chi^{2}$ & 64.78 & 22.98 \\
& P-value & 0.000 & 0.002 \\
& Pseudo R ${ }^{2}$ & 0.205 & 0.123 \\
3 & & & \\
& Wald $\chi^{2}$ & 102.0 & 26.42 \\
& P-value & 0.000 & 0.000 \\
& Pseudo R & 0.216 & 0.109 \\
4 & & & \\
& Wald $\chi^{2}$ & 62.63 & 33.85 \\
& P-value & 0.000 & 0.000 \\
& Pseudo R & 0.177 & 0.106 \\
\hline
\end{tabular}

The inverse probability weights are the ratio of the predicted probability of participation from the in the restricted model to that of the unrestricted model. The mean weight after the first round is 1.01 with a maximum of 1.55 and minimum of 0.65 . These weights are used in all the analyses in this paper. 


\section{Appendix B: HSNP Adherence to Selection and Precision of Targeting}

This appendix provides a more detailed analysis of HSNP targeting. We first examine the adherence to selection by targeting criteria, finding that the program's exogenous selection criteria correctly predict HSNP participation in $85.9 \%$ of the observations among the general population and $76.5 \%$ among households within target communities while transfers were taking place there. We then determine, to what degree HSNP successfully targeted its general target population; "those households that are chronically food insecure" or "have low consumption expenditure and low asset holdings" and/or "[a]re already reliant on food aid" (Hurrell, MacAuslan \& Merttens 2008, p8). We find that HSNP does target those households with fewer assets and lower consumption per AE.

\section{Adherence to selection}

To examine adherence to selection criteria we focus only on the data from a single year: 2011. 2011 is ideal because by then all target communities had begun receiving transfers, so that comparisons are made across targeting criteria in the same period, all targeting in this sample takes place before the 2011 survey, and it avoids 2012, which seems to have the most abnormalities related to entrance and exit from the HSNP.

\section{Pension Communities}

In pension communities, all individuals 55 years and older should have been eligible to receive HSNP transfers and no households without a member older than 54 should have received transfers. Households with more than one "pensioner" should have received payments for each, although we do not examine the data for compliance in that dimension.

In 2011, 82\% of survey households in the pensioner-targeted communities of El Gade, Logo, and Lontolio were correctly targeted (Table B1). The inclusion error rate was 5\% and the exclusion error rate is $13 \%$. Households meeting the targeting criteria (being above rather than under the target age of 55) participate in HSNP at a rate that is $50 \%$ higher than that of non-eligible households.

Table B1. HSNP adherence to selection in pension communities: El Gade, Logo \& Lontolio (2011)

\begin{tabular}{lcc}
\hline \hline & \multicolumn{2}{c}{ Criteria } \\
HSNP & Age $\frac{}{<55}$ & Age $\geq 55$ \\
\hline Non-participant & 0.65 & 0.13 \\
Participant & 0.05 & 0.17 \\
\hline
\end{tabular}

\section{Dependency Ratio Communities}

Within communities that were randomly selected for the dependency ratio targeting scheme, all households with a dependency ratio greater than $57 \%$ should be eligible to receive transfers (Hurrell, MacAuslan \& Merttens 2008). Dependents include any household members under 18, over 55, disabled, or chronically ill (Hurrell \& Sabates-Wheeler 2013). None of the dependency ratio targeted communities had begun receiving payments by the time of the 2009 IBLI survey. By the 2011 IBLI survey, 106 households in dependency ratio targeted communities were receiving transfers. Of those participants, 53\% met the dependency ratio criteria. The average adherence to selection criteria across all categories is $56 \%$.

Table B2. HSNP adherence to selection in dependency ratio communities: Kargi and Kurkum (2011)

\section{Criteria}

\begin{tabular}{lcc} 
HSNP & Dep. Ratio $<0.57$ & Dep. Ratio $\geq 0.57$ \\
\hline Non-participant & 0.08 & 0.08 \\
Participant & 0.43 & 0.48 \\
\hline
\end{tabular}




\section{Community Targeting}

Within community targeted locations, households judged most in need of transfers were collectively selected by the community. $50 \%$ of each community was to be targeted this way (Hurrell, MacAuslan \& Merttens 2008). Because there is no single variable or criterion that determines eligibility, an analysis of selection adherence is not meaningful. Instead, we test the variables used as controls for selection by the evaluation organizations for their power to predict which households are most likely to receive HSNP transfers. ${ }^{42}$ This exercise serves two purposes. First, it tests if there is a systematic process for determining who was selected by the community. Second, we can determine if the set of controls used by the evaluation organization can be used to generate a community based need score that is appropriate as a statistical control in the impact evaluation. ${ }^{43}$

To test for the predictive power of the controls, HSNP participation was regressed onto a set of household characteristics using a probit regression in order to estimate the propensity of HSNP participation. ${ }^{44}$ Those with a propensity score greater than 0.5 during the period in which HSNP transfers commenced their community, were categorized as community targeted households while those falling below that threshold were considered untargeted. This approach correctly predicts $74 \%$ of household participation in community based targeting communities (Table B3).

Table B3. Community based targeting: Bubisa, Dakabaricha, Dirib Gombo \& Kalacha (2011)

\begin{tabular}{lcc}
\hline & \multicolumn{2}{c}{ Criteria } \\
HSNP & Propensity Score $<0.50$ & Propensity Score $\geq 0.50$ \\
\hline Non-participant & 0.17 & 0.20 \\
Participant & 0.06 & 0.57 \\
\hline
\end{tabular}

The preceding analysis reveals that the systematic selection process outlined by the program strongly impacts who receives transfers. Within HSNP targeted communities, the average rate of adherence to selection criteria rate is $76.5 \%$. But it is also clear from this analysis that the selection criteria are not the only factors that determine participation in the program. Therefore, our analysis proceeds with the assumption that observed HSNP participation depends as well on other, potentially endogenous, factors. ${ }^{45}$

\section{Precision of Targeting}

The precision of targeting measures the program's record of providing transfers to the individuals that the program aims to assist. In this case, the target population consists of those households that are chronically food insecure or "have low consumption expenditure and low asset holdings; and/or [a]re already reliant on food aid" (Hurrell, MacAuslan \& Merttens 2008, p8). The precision of the HSNP program targeting is examined by individually regressing HSNP participation on the three criteria for chronically food insecure

\footnotetext{
${ }^{42}$ HSNP evaluation was contracted to Oxford Policy Management (OPM), working with the Institute of Development Studies (IDS) at the University of Sussex (UK).

43 The rationale for using OPM and IDS controls is our assumption that they had information on how the HSNP field workers guided the selection process and recorded trends in how the communities selected households.

${ }^{44}$ Household level controls included: age of head of household, maximum age of household female head of household, widowed head of household, adult equivalents, dependency ratio, food aid, household type (fully settled, partially settled, nomadic), chronically ill or disabled members (dummy), savings (dummy), consumption per AE, proportion of consumption from food aid, asset index, and sublocation.

${ }^{45}$ Interestingly, there is also a great deal of variation in participation rate between HSNP targeted communities in our data. The authors have no hypothesis as to why that might be.
} 
households specifically mentioned in the monitoring and evaluation strategy: total consumption per AE, proportion of consumption from food aid, and an index of asset holdings in the target communities. ${ }^{46}$ Analysis is performed using data collected in 2009 to examine pre-transfer status.

The point estimates for the asset index and consumption per AE are all in the expected direction, negative, and statistically significant. The point estimate for reliance on food aid is in the expected direction but statistically indistinguishable from zero (Column 1, Table B4). The data used in this analysis were collected after the first transfers were made in 5 target communities ${ }^{47}$ Although it seems unlikely that the few prebaseline transfers are impacting these results, we perform a second analysis, restricting the data to those communities that had not yet received transfers at the survey baseline. In this restricted case, the magnitudes of each the coefficients increases and their direction and pattern of statistical significance remain the same (Column 2, Table B4). Thus it seems that the HSNP targeting is at least partially meeting it goal of targeting the food secure, although they are missing those households with a high percent of food from food aid. ${ }^{48}$

Table B4. Probit regressions of HSNP participation on proxies of food insecurity

\begin{tabular}{|c|c|c|}
\hline \multirow[b]{2}{*}{ Proxies of Food Insecurity } & \multicolumn{2}{|c|}{$\underline{\text { Average Marginal Effects }}$} \\
\hline & Target Communities & Restricted Target Communities ${ }^{1}$ \\
\hline \multirow[t]{3}{*}{ Asset Index } & $-0.0842 * *$ & $-0.192 * * *$ \\
\hline & $(0.0362)$ & $(0.0649)$ \\
\hline & {$[9.571]$} & {$[7.052]$} \\
\hline \multirow[t]{3}{*}{ Percent Food from Aid } & 0.0241 & -0.239 \\
\hline & $(0.227)$ & $(0.306)$ \\
\hline & [8.976] & [6.014] \\
\hline \multirow[t]{3}{*}{ Consumption per $\mathrm{AE}$} & $-0.0299 *$ & $-0.0652 * *$ \\
\hline & $(0.0181)$ & $(0.0322)$ \\
\hline & [8.708] & {$[7.237]$} \\
\hline Observations & 570 & 236 \\
\hline
\end{tabular}

\footnotetext{
${ }^{46}$ See Appendix A for a full description of the asset index and its construction.

${ }^{47}$ Using target start dates for each community, we estimate that the following transfers had been made before our baseline data had been collected: 3 in Dakabaricha, 3 in Logo Logo, 2 in El Gade, 2 in Kalacha, 1 in Dirbi Gombo.

${ }^{48}$ As a point of interest, the correlation between the asset index and percent food from aid is -0.10 , P-value $=0.00$, and between consumption per $\mathrm{AE}$ is -0.26 , P-value 0.00 , both in the expected direction if increased assets, reduced reliance on food aid, and increased consumption per $\mathrm{AE}$ are all indicators of food security.
} 


\section{Appendix C: HSNP Instruments}

We use the variation in HSNP participation around the targeting criteria threshold to instrument for HSNP participation. For the thresholds to serve as valid instruments they must be exogenous and correctly identify an increase in participation. This appendix first examines household survey data to determine if there is evidence that households manipulate their reported structure (size, age, etc.) so as to fit the target criteria, which would endogenize satisfaction of eligibility criteria.

Both analyses use a regression discontinuity design to test for a discontinuity in the probability density of responses for each of the criteria characteristics at the threshold. A discontinuity in the distribution of ages or dependency ratios at the threshold would suggest that households manipulated their self-reported characteristics to fit the criteria, calling into question the exogeneity of our instruments. Conversely, a lack of a discontinuity in the likelihood of HSNP participation at the eligibility thresholds would call into question the relevance of our instruments. We find no evidence of such manipulations. We then find that the targeting thresholds do identify a positive "jump" in the likelihood of HSNP participation, supporting their use as instruments.

To test for discontinuities in either maximum age or dependency ratio data, we estimate the distribution of each variable by counting the number of observations for each reported age and each reported dependency ratio. We then regress that count onto an indicator of that the household meets the eligibility threshold, a third order polynomial of the running variable (age or dependency ratio), and a set of interactions of those polynomial terms with an eligibility threshold indicator variable. If households adjust their reported demographics to meet the HSNP eligibility criteria, we expect there to be a discontinuity in the number of households near the threshold. Such activity would be evident in significant parameter estimates for the threshold variables. We find no evidence that household responses to maximum household age (Coef. Est.= 1.218, Std. Err.= 1.307) or dependency ratio (Coef. Est.=-2.213, Std. Err.=3.917) are manipulated to meet the HSNP eligibility criteria during the targeting period in the targeted communities (Table C1.). ${ }^{49}$

\footnotetext{
${ }^{49}$ It is uninformative to perform a similar analysis on the estimated community score because that is smooth by construction (see Appendix B for details on the construction of the community score).
} 
Table C1. The observed probability distributions of reported age and dependency ratio (DR).

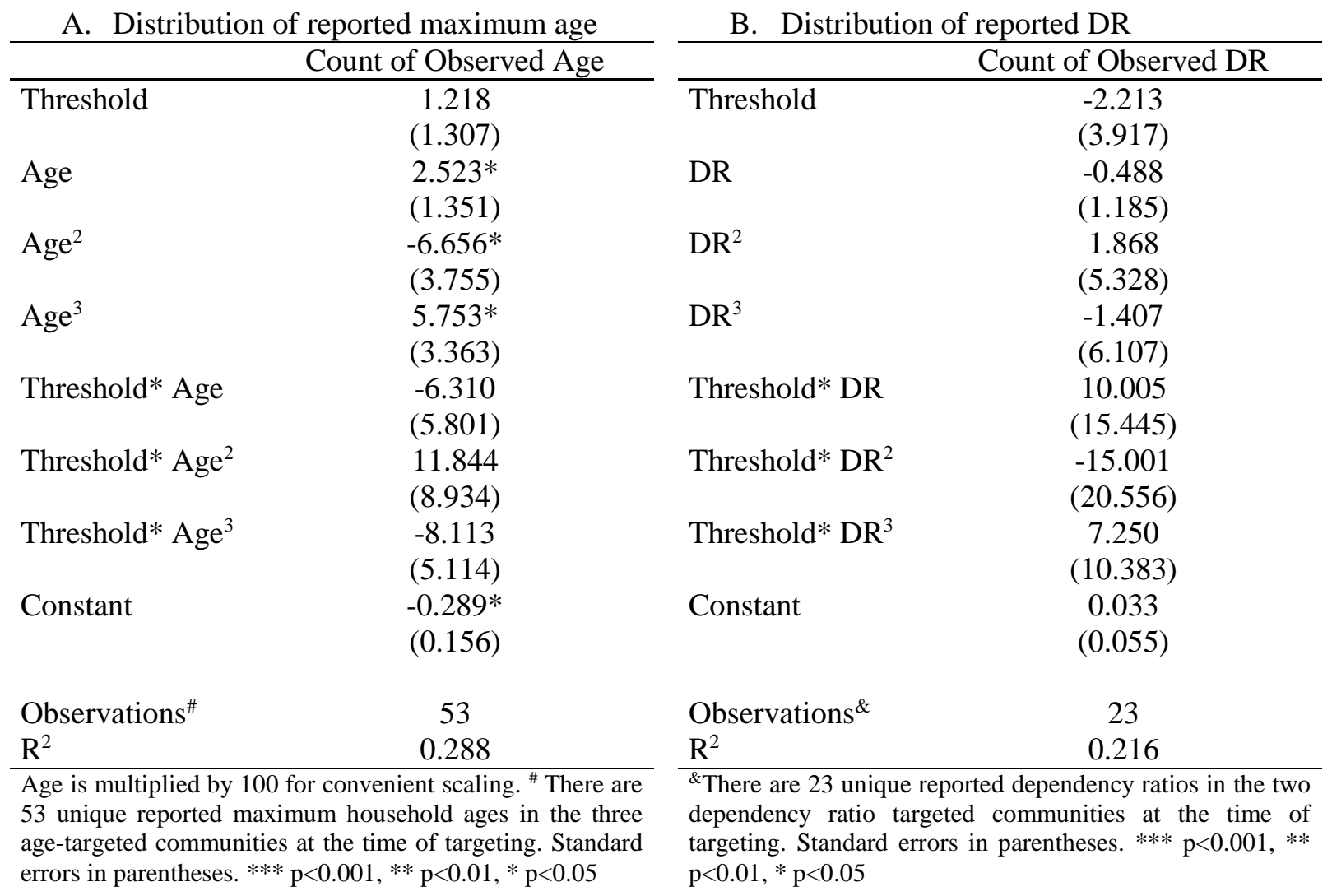

The validity of the HSNP instruments also requires that the thresholds are correlated with participation. Household participation is regressed on a third order polynomial of the three targeting variables and the intent to treat indicator which is equal to one if the household lives in an HSNP target community and meets the targeting criteria of their community during the targeting period. The strength of the instrument rests on the statistical significance of the coefficient estimates associated with the IIT indicator and thus the variation in HSNP participation captured by the eligibility thresholds. The ITT coefficient estimate is positive and significant, confirming its relevance of the instrument (Table C2).

Table C2. OLS analysis of intent to treat (ITT) indicator and HSNP participation

\begin{tabular}{lc}
\hline & HSNP Participant \\
\hline ITT & $\left(0.615^{*} * *\right.$ \\
& \\
& 7,021 \\
Observations & 0.519
\end{tabular}




\section{Appendix D: IBLI Instruments}

For the coupons to be valid instruments they must be random and correlated with purchases. Table D1 provides a balancing test of key variables between those respondents who received coupons and those who did not. The balancing test is performed on the data from the season immediately preceding each coupon distribution, so that the data do not capture households' responses to receiving a coupon (i.e., associated with purchasing insurance). There are small, statistically significant differences between recipients and nonrecipients in specific periods (gender in SRSD10 and LRLD11, dependency ratio in SRSD09 and LRLD12, and income in LRLD12) but none that systematically appear across all coupon distribution periods and no more than one would expect randomly. So premium discount coupon distribution indeed appears random, as designed.

Table D1. Test of balance between coupon recipients and non-recipients

\begin{tabular}{|c|c|c|c|c|c|c|c|}
\hline Season & Variable & No Coupon & Std. Err. & Coupon & Std. Err. & Difference & t-statistic \\
\hline \multirow[t]{8}{*}{ SRSD09 } & Head age & 47.2 & 1.93 & 48.4 & 1.82 & 1.18 & 0.45 \\
\hline & Head gender & 0.61 & 0.04 & 0.61 & 0.03 & 0.00 & 0.02 \\
\hline & Members & 5.13 & 0.15 & 5.31 & 0.13 & 0.17 & 0.88 \\
\hline & Dependency Ratio & 0.58 & 0.02 & 0.62 & 0.01 & 0.04 & $1.69 *$ \\
\hline & Herd size (TLU) & 14.0 & 1.41 & 13.2 & 0.96 & -0.83 & -0.49 \\
\hline & Income (Ksh/month) & 3,440 & 558 & 4,480 & 538 & 1,050 & 1.35 \\
\hline & Asset Index & -0.17 & 0.05 & -0.08 & 0.07 & 0.08 & 0.94 \\
\hline & Consumption per $\mathrm{AE}$ & 1,620 & 80.8 & 1,660 & 95.3 & 40 & 0.32 \\
\hline \multirow[t]{8}{*}{ SRSD10 } & Head age & 46.9 & 1.96 & 48.7 & 1.59 & 1.87 & 0.74 \\
\hline & Head gender & 0.64 & 0.04 & 0.55 & 0.04 & -0.09 & $-1.69 *$ \\
\hline & Members & 5.35 & 0.15 & 5.53 & 0.15 & 0.18 & 0.85 \\
\hline & Dependency Ratio & 0.63 & 0.01 & 0.62 & 0.01 & -0.01 & -0.59 \\
\hline & Herd size (TLU) & 12.3 & 1.03 & 14.5 & 1.11 & 2.21 & 1.45 \\
\hline & Income (Ksh/month) & 8,680 & 697 & 9,881 & 704 & 1,200 & 1.21 \\
\hline & Asset Index & -0.39 & 0.03 & -0.33 & 0.04 & 0.06 & 1.29 \\
\hline & Consumption per AE & 1,730 & 153 & 1,580 & 100 & -141 & -0.77 \\
\hline \multirow[t]{8}{*}{ LRLD11 } & Head age & 45.9 & 1.50 & 48.4 & 1.01 & 2.52 & 1.39 \\
\hline & Head gender & 0.66 & 0.04 & 0.56 & 0.04 & -0.09 & $-1.72 *$ \\
\hline & Members & 5.78 & 0.17 & 5.81 & 0.14 & 0.03 & 0.13 \\
\hline & Dependency Ratio & 0.58 & 0.02 & 0.58 & 0.02 & 0.00 & -0.03 \\
\hline & Herd size (TLU) & 11.4 & 0.99 & 11.7 & 0.77 & 0.25 & 0.20 \\
\hline & Income (Ksh/month) & 10,500 & 1,010 & 9,250 & 520 & $-1,260$ & -1.10 \\
\hline & Asset Index & -0.13 & 0.07 & -0.10 & 0.05 & 0.03 & 0.34 \\
\hline & Consumption per $\mathrm{AE}$ & 1,930 & 86.1 & 1,970 & 75.6 & 36.3 & 0.32 \\
\hline \multirow[t]{8}{*}{ LRLD12 } & Head age & 46.3 & 1.32 & 49.1 & 1.02 & 2.74 & 1.64 \\
\hline & Head gender & 0.63 & 0.04 & 0.57 & 0.04 & -0.06 & -1.10 \\
\hline & Members & 6.10 & 0.19 & 6.21 & 0.14 & 0.11 & 0.48 \\
\hline & Dependency Ratio & 0.64 & 0.01 & 0.60 & 0.02 & -0.04 & $-1.78 *$ \\
\hline & Herd size (TLU) & 10.6 & 0.88 & 11.1 & 0.72 & 0.50 & 0.43 \\
\hline & Income (Ksh/month) & 9,070 & 689 & 10,900 & 845 & 1,880 & $1.72 *$ \\
\hline & Asset Index & 0.03 & 0.05 & 0.14 & 0.06 & 0.10 & 1.24 \\
\hline & Consumption per AE & 1,418 & 79.7 & 1,541 & 78.5 & 123 & 1.10 \\
\hline
\end{tabular}


To be valid instruments, the discount coupon must also be correlated with demand for insurance. We test for correlation with both uptake (a dummy variable equal to one if the household purchased IBLI that season) and the continuous level of purchase, measured in TLUs of coverage. Our instrumental variable is the premium discount (in percent) that a household received by way of a coupon.

Table D2. Predictive power of the discount coupons on purchases

\begin{tabular}{lcc}
\hline & $\begin{array}{c}\text { Dummy } \\
(=1 \text { if purchased) }\end{array}$ & $\begin{array}{c}\text { Level } \\
\text { (TLUs insured) }\end{array}$ \\
\hline Premium Discount $(\%)$ & $0.405^{* * *}$ & $1.396^{* * *}$ \\
& $(0.058)$ & $(0.211)$ \\
Observations & & \\
$\mathrm{R}^{2}$ & 7,027 & 7,027 \\
\hline
\end{tabular}

Regression includes the following covariates: adult equivalence, age of head, age of head squared, maximum education in household, a dummy indicating the head of household is a widow, the current season's predicted livestock mortality rate, the current season's predicted livestock mortality rate squared, division-period dummies and the three HSNP targeting characteristics to the first, second, and third power. Clustered and robust standard errors in parentheses. $* * * \mathrm{p}<0.01$, $* *$ $\mathrm{p}<0.05, * \mathrm{p}<0.1$ 


\section{Appendix E: Further Analysis of Households' Responses to Shocks}

Analysis of response to covariate shocks found that households increase livestock sales during covariate shock years but that neither HSNP participation nor IBLI coverage impact that response significantly (Table7). If households face a great deal of idiosyncratic risk, it may be that our covariate shock indicator misses many of the shocks that households face. To allow for individual shocks, we define a shock season as any season in which the household experiences greater than a 15\% livestock mortality rate. By this definition, households face shocks in about $30 \%$ of our observations. To learn about the impact of participation or coverage one should add the $\mathrm{P} / \mathrm{C}$ coefficient estimate to the $\mathrm{P} / \mathrm{C}$ *Shock coefficient estimate. Our analysis finds a pattern consistent with those from the covariate definitions of shock; that households increase livestock sales during shock seasons, that IBLI increases livestock sales in "non-shock" seasons, and there is no evidence that HSNP participation of IBLI coverage reduces livestock sales during shock seasons.

Table E1. The relationship between individually defined shocks, HSNP participation and IBLI coverage on the sales of livestock

\begin{tabular}{|c|c|c|}
\hline & $\begin{array}{c}\text { HSNP } \\
\text { Participation } \\
\end{array}$ & IBLI Coverage (TLUs) \\
\hline Shock & $\begin{array}{l}0.137 * * \\
(0.0628)\end{array}$ & $\begin{array}{c}0.198 * * * \\
(0.0625)\end{array}$ \\
\hline Participation/ Coverage (P/C) & $\begin{array}{c}0.107 \\
(0.149)\end{array}$ & $\begin{array}{c}0.154^{*} \\
(0.0806)\end{array}$ \\
\hline P/C*Shock & $\begin{array}{c}0.155 \\
(0.161)\end{array}$ & $\begin{array}{l}-0.0713 \\
(0.139)\end{array}$ \\
\hline $\mathrm{H} 0: \mathrm{P} / \mathrm{C}+\mathrm{P} / \mathrm{C} *$ Shock $=0$ (z-score $)$ & 1.187 & 0.599 \\
\hline Observations & 6,551 & 6,557 \\
\hline Households & 895 & 895 \\
\hline Model F-statistic & 5.025 & 5.477 \\
\hline
\end{tabular}

To test to the impact of current coverage and distress sales while controlling for past and coming shocks, we include both future and lagged shock dummies. Shocks are defined as any period during which covariate losses are greater than 0.15 . The estimates continue to point towards little changes to sales associated with HSNP participation (although there is some indication that HNSP participants reduce livestock sales during non-shock seasons by this specification) and increased livestock sales by the insured during non-shock periods. 
Table E2. Current livestock sales in response to past, current, and coming covariate shocks

\begin{tabular}{|c|c|c|}
\hline & HSNP Participation (IV) & IBLI Coverage (IV) \\
\hline Past Shock (t-1) & $\begin{array}{c}0.125 \\
(0.229)\end{array}$ & $\begin{array}{c}0.278 \\
(0.198)\end{array}$ \\
\hline Shock $(\mathrm{t})$ & $\begin{array}{c}0.874 * * * \\
(0.313)\end{array}$ & $\begin{array}{c}0.876 * * * \\
(0.295)\end{array}$ \\
\hline Coming Shock $(t+1)$ & $\begin{array}{c}-3.096 * * \\
(1.265)\end{array}$ & $\begin{array}{l}-1.925 \\
(1.553)\end{array}$ \\
\hline Participation/Coverage (P/C) & $\begin{array}{r}-0.683^{*} \\
(0.359)\end{array}$ & $\begin{array}{l}0.835^{*} \\
(0.461)\end{array}$ \\
\hline P/C*Past Shock & $\begin{array}{c}0.693 * * \\
(0.313)\end{array}$ & $\begin{array}{l}-0.630 \\
(0.466)\end{array}$ \\
\hline $\mathrm{P} / \mathrm{C} *$ Shock & $\begin{array}{c}0.155 \\
(0.218)\end{array}$ & $\begin{array}{l}-0.237 \\
(0.153)\end{array}$ \\
\hline $\mathrm{P} / \mathrm{C} *$ Coming Shock & $\begin{array}{l}0.804 * * * \\
(0.274)\end{array}$ & $\begin{array}{l}-0.654 \\
(0.456)\end{array}$ \\
\hline Observations & 4,680 & 4,686 \\
\hline Households & 833 & 833 \\
\hline Model F-stat & 4.207 & 4.166 \\
\hline
\end{tabular}




\section{Appendix F: Pooled Instrumental Variables Estimates}

In the event that time invariant household characteristics do not play a role in outcomes, the fixed effects model is inefficient. We therefore re-estimate in this appendix, using a pooled model, as a robustness check. We continue to use the instrumental variables described in the main body of the text (i.e., intent to treat for HSNP and discount coupons for IBLI). We also include a time invariant indicator equal to one if the household participated in the IBLI educational game, which is random and has a statistically significant positive impact on IBLI uptake (Jensen, Mude \& Barrett 2014).

The pooled estimates are, for the most part, very similar to the fixed effects estimates. The most significant changes are associated with HSNP participation and a much more ambiguous impact on household mobility (Table F1) and a much stronger relationships between both programs and asset holdings, although the programs' impacts change with depth of participation (Table F2). These findings do not support the hypothesis that the pooled model is sufficient and more efficient than the fixed effect model for these analysis, as many of the estimates change sign and lose statistical significance with pooling. 
Table F1. Impact of HSNP participation and IBLI coverage on production strategies and outcomes

\begin{tabular}{|c|c|c|c|c|}
\hline \multirow[b]{2}{*}{ Dependent Variable } & \multicolumn{2}{|c|}{ HSNP (Pooled-IV) } & \multicolumn{2}{|c|}{$\underline{\text { IBLI (Pooled-IV) }}$} \\
\hline & $\begin{array}{c}\text { Previous } \\
\text { Participation } \\
\end{array}$ & $\begin{array}{c}\text { Current } \\
\text { Participation }\end{array}$ & $\begin{array}{l}\text { Previous } \\
\text { Coverage }\end{array}$ & $\begin{array}{c}\text { Current } \\
\text { Coverage (TLU) }\end{array}$ \\
\hline \multicolumn{5}{|l|}{ Production strategies: } \\
\hline Herd Size & $\begin{array}{c}-1.334 * * * \\
(0.429)\end{array}$ & $\begin{array}{l}-2.597 \\
(2.555) \\
{[7.846]}\end{array}$ & $\begin{array}{l}-11.32 * * * \\
(2.534)\end{array}$ & $\begin{array}{l}-0.0175 \\
(1.171) \\
{[8.508]}\end{array}$ \\
\hline $\begin{array}{l}\text { Veterinary Expenditures } \\
(\mathrm{KSH})\end{array}$ & $\begin{array}{l}-16.03 \\
(66.97)\end{array}$ & $\begin{array}{l}117.7 \\
(246.5) \\
{[11.65]}\end{array}$ & $\begin{array}{c}182.4 \\
(268.0)\end{array}$ & $\begin{array}{l}-3.870 \\
(101.9) \\
{[11.30]}\end{array}$ \\
\hline $\begin{array}{l}\text { Veterinary } \\
\text { Expenditures/TLU } \\
(\mathrm{KSH})\end{array}$ & $\begin{array}{l}7.470 \\
(8.760)\end{array}$ & $\begin{array}{c}29.98 \\
(32.94) \\
{[5.975]}\end{array}$ & $\begin{array}{c}90.06 \\
(61.06)\end{array}$ & $\begin{array}{l}-29.93 * \\
(17.71) \\
{[4.820]}\end{array}$ \\
\hline $\begin{array}{l}\text { Ratio of Herd Held at } \\
\text { Home }\end{array}$ & $\begin{array}{c}0.0105 \\
(0.0122)\end{array}$ & $\begin{array}{c}-0.0401 \\
(0.0558) \\
{[11.30]}\end{array}$ & $\begin{array}{c}0.0380 \\
(0.0756)\end{array}$ & $\begin{array}{c}-0.0566 \\
(0.0381) \\
{[10.57]}\end{array}$ \\
\hline $\begin{array}{l}\text { Household is Partially or } \\
\text { Fully Mobile A }\end{array}$ & $\begin{array}{c}0.0157 \\
(0.0134)\end{array}$ & $\begin{array}{c}-0.00308 \\
(0.0641) \\
{[53.06]}\end{array}$ & $\begin{array}{c}-0.140 \\
(0.0955)\end{array}$ & $\begin{array}{c}0.00363 \\
(0.0438) \\
{[49.27]}\end{array}$ \\
\hline \multicolumn{5}{|l|}{ Production outcomes: } \\
\hline Milk income $(\mathrm{KSH})$ & $\begin{array}{c}69.74 \\
(248.5)\end{array}$ & $\begin{array}{c}243.1 \\
(914.5) \\
{[12.48]}\end{array}$ & $\begin{array}{c}1,056 \\
(1,124)\end{array}$ & $\begin{array}{c}580.0 \\
(640.5) \\
{[12.64]}\end{array}$ \\
\hline $\begin{array}{l}\text { Milk income per TLU } \\
(\mathrm{KSH})\end{array}$ & $\begin{array}{l}76.98 * * * \\
(17.30)\end{array}$ & $\begin{array}{l}-115.1 \\
(73.63) \\
{[18.09]}\end{array}$ & $\begin{array}{l}414.7 * * * \\
(131.6)\end{array}$ & $\begin{array}{c}54.83 \\
(59.64) \\
{[15.11]}\end{array}$ \\
\hline Livestock losses & $\begin{array}{c}-0.320 * * \\
(0.159)\end{array}$ & $\begin{array}{c}0.437 \\
(0.774) \\
{[9.342]}\end{array}$ & $\begin{array}{c}-1.541^{* *} \\
(0.655)\end{array}$ & $\begin{array}{l}-0.0256 \\
(0.299) \\
{[8.383]}\end{array}$ \\
\hline Livestock Mortality Rate & $\begin{array}{l}-0.0182 * * \\
(0.00709)\end{array}$ & $\begin{array}{c}0.0446 * \\
(0.0235) \\
{[27.19]}\end{array}$ & $\begin{array}{l}-0.00381 \\
(0.0339)\end{array}$ & $\begin{array}{c}-0.0190 \\
(0.0135) \\
{[26.34]}\end{array}$ \\
\hline
\end{tabular}

Both models include the following covariates: adult equivalence, age of head, age of head squared, maximum education in household, a dummy indicating the head of household is a widow, the current season's predicted livestock mortality rate, the current season's predicted livestock mortality rate squared, division-period dummies and the three HSNP targeting characteristics to the first, second, and third power. ${ }^{\mathrm{A}} \mathrm{A}$ linear probability model is used to estimate the likelihood that a household is partially or fully mobile. Clustered and robust standard errors in parentheses. Model F-statistics in brackets. *** $\mathrm{p}<0.01, * * \mathrm{p}<0.05, * \mathrm{p}<0.1$ 
Table F2. The impact of HSNP transfers and IBLI coverage on household welfare (Pooled estimates)

\begin{tabular}{|c|c|c|c|c|}
\hline \multirow[b]{2}{*}{ Dependent Variable } & \multicolumn{2}{|c|}{ HSNP (Pooled-IV) } & \multicolumn{2}{|c|}{ IBLI (Pooled-IV) } \\
\hline & $\begin{array}{c}\text { Previous } \\
\text { Participation }\end{array}$ & $\begin{array}{c}\text { Current } \\
\text { Participation }\end{array}$ & $\begin{array}{l}\text { Previous } \\
\text { Coverage }\end{array}$ & $\begin{array}{c}\text { Current } \\
\text { Coverage } \\
\text { (TLU) }\end{array}$ \\
\hline Consumption per $\mathrm{AE}$ & $\begin{array}{l}-55.71 * \\
(29.12)\end{array}$ & $\begin{array}{c}347.9 * * \\
(169.8) \\
{[31.05]}\end{array}$ & $\begin{array}{l}-42.83 \\
(187.1)\end{array}$ & $\begin{array}{c}149.5 \\
(93.11) \\
{[27.71]}\end{array}$ \\
\hline Asset Index & $\begin{array}{c}-7.295^{* * *} * \\
(2.374)\end{array}$ & $\begin{array}{c}43.11 * * * \\
(12.86) \\
{[19.14]}\end{array}$ & $\begin{array}{c}51.21 * * * \\
(14.11)\end{array}$ & $\begin{array}{c}-8.986 * \\
(5.194) \\
{[15.93]}\end{array}$ \\
\hline Income per $\mathrm{AE}$ & $\begin{array}{l}-27.29 \\
(45.03)\end{array}$ & $\begin{array}{c}231.7 \\
(263.2) \\
{[24.17]}\end{array}$ & $\begin{array}{l}-69.34 \\
(241.2)\end{array}$ & $\begin{array}{l}212.6 \\
(156.0) \\
{[24.40]}\end{array}$ \\
\hline School Absenteeism & $\begin{array}{r}-0.0971 \\
(0.127)\end{array}$ & $\begin{array}{c}-0.0851 \\
(0.745) \\
{[4.482]}\end{array}$ & $\begin{array}{l}-0.165 \\
(0.519)\end{array}$ & $\begin{array}{c}0.491 \\
(0.526) \\
{[3.570]}\end{array}$ \\
\hline School Enrollment & $\begin{array}{c}0.0164 \\
(0.0138)\end{array}$ & $\begin{array}{c}0.0421 \\
(0.0596) \\
{[17.44]}\end{array}$ & $\begin{array}{c}0.169 \\
(0.113)\end{array}$ & $\begin{array}{c}0.0145 \\
(0.0348) \\
{[13.72]}\end{array}$ \\
\hline MUAC & $\begin{array}{c}-0.00268 \\
(0.0548)\end{array}$ & $\begin{array}{c}-0.0256 \\
(0.290) \\
{[6.825]}\end{array}$ & $\begin{array}{l}-0.384 \\
(0.395)\end{array}$ & $\begin{array}{c}0.175 \\
(0.163) \\
{[5.583]}\end{array}$ \\
\hline $\operatorname{Pr}(\mathrm{MUAC} \leq 12.5 \mathrm{~cm})$ & $\begin{array}{l}0.00270 \\
(0.0180)\end{array}$ & $\begin{array}{c}0.0342 \\
(0.0673) \\
{[1.888]}\end{array}$ & $\begin{array}{c}-0.0398 \\
(0.0849)\end{array}$ & $\begin{array}{c}0.0501 \\
(0.0399) \\
{[1.582]}\end{array}$ \\
\hline
\end{tabular}

Both models include the following covariates: adult equivalence, age of head, age of head squared, maximum education in household, a dummy indicating the head of household is a widow, the current season's predicted livestock mortality rate, the current season's predicted livestock mortality rate squared, division-period dummies and the three HSNP targeting characteristics to the first, second, and third power. Clustered robust standard errors in parentheses. Model F-statistic in brackets. $* * * \mathrm{p}<0.01$, $* * \mathrm{p}<0.05, * \mathrm{p}<0.1$. 


\section{Appendix G: Heterogeneity in Average Program Effects}

In order to examine the data for heterogeneity in impacts we take a slightly different approach than we have in the earlier analysis. In the earlier analysis we were most interested in learning how changes in HSNP participation or IBLI coverage impacted certain outcomes. Those results provide conclusions such as, "an additional season of HSNP transfers is associated with an average increase of $63.65 \mathrm{KSH}$ in value of milk per TLU". Here, we are most interested in examining the total effect of each of these programs on individuals and how that impact changes across a certain parameters of interest. To estimate these total effects, we begin by re-estimating equation (1) with the addition of an interaction term. We interact each indicator of program participation with a variable that we suspect is associated with heterogeneity in impacts.

Equation (1) can be rewritten to include interactions between the VOI and the variable associated with heterogeneity, which we will call $D_{i t}$, as follows:

$$
\begin{gathered}
y_{i t}=\beta_{0}+V O I_{i t}{ }^{\prime} \beta_{1}+\left[D_{i t} V_{O I}\right]_{i t} \beta_{2}+x_{i t}^{\prime} \beta_{3}+c_{i}+\varepsilon_{i t} \\
V O I_{i t}=\left\{\left(H S N P_{i t}, H S N P C_{i t}\right),\left(I B L I_{i t}, I B L I C_{i t}\right)\right\} \\
D_{i t}=\text { Heterogenous Dimension }
\end{gathered}
$$

For a participating individual, the effect of participation in any time period is captured by $V O I_{i t}{ }^{\prime} \beta_{1}+$ $\left[D_{i t} V I_{i t}\right]^{\prime} \beta_{2}$. We are then faced with deciding which values of the VOI and which dimensions $D$ are most interesting.

Although examining variation in impacts across program related variables (i.e. basis risk, indemnity payments, HSNP eligibility criteria) is important, to provide an interesting analysis of heterogeneity in both programs simultaneously, $D$ should equally important to both programs. $D$ also needs to be unaffected by participation in either program. We choose initial livestock holdings as our dimension of interest, because livestock is an indicator of productive capital and wealth in this region, it is relevant to both programs, and the data were collected before either program started. We generate the variable $D$, which is a dummy variable that is equal to one if the household is initially (during the pre-survey data collection if September, 2009) has fewer than 10 TLUs. ${ }^{50}$ Ten TLUs is chosen as the cutoff because it falls near, but below, estimates of an unstable equilibrium in herd size dynamics which could feasibly interact with the effects of HSNP transfers or IBLI coverage (Lybbert et al. 2004). There are 328 households in the low TLU group and 596 households in the high TLU group.

Heterogeneity in a program's impacts can be the result of variation in household response to the program as well as variation in participation in the program. Both dimensions are of importance here because we do expect program participation to vary across herd size and the impacts of each program could easily vary across initial wealth status. Estimating Equation 1' allows for variation in response. We then use the final

\footnotetext{
${ }^{50}$ There has been some speculation that IBLI would most benefit those falling in the middle class because the poor are too poor to purchase and the rich are likely to already have greater access to alternative risk pooling tools. But, that argument is fundamentally an argument based on demand not impacts. Even so, in work not included in this appendix, we did estimate the coefficient and impacts of HSNP participation and IBLI coverage allowing for variation across low ( $<10 \mathrm{TLU})$, medium $(10 \leq \mathrm{TLU}<20)$, and high $(20 \leq \mathrm{TLU})$ initial livestock holdings. Those estimates are much less stable than the two-group estimates reported and do not point towards a more highly impacted middle TLU group.
} 
round, within-TLU-group expected participation among participants as the values for the VOI (Table G1). There is statistically significant variation in participation rates across $D$ in both programs, but practically speaking the differences are quite small. ${ }^{51}$ Specifically, the low TLU group participates in the HSNP program more and insures less with IBLI.

Table G1. Average final period program values in high and low TLU households among participants.

\begin{tabular}{lcccccc}
\hline & \multicolumn{4}{c}{ TLU Class } & & \\
\cline { 2 - 5 } & \multicolumn{2}{c}{$\begin{array}{c}\text { High } \\
(\mathrm{N}=596)\end{array}$} & \multicolumn{2}{c}{$\begin{array}{c}\text { Low } \\
(\mathrm{N}=328)\end{array}$} & Difference & F-statistic \\
\hline HSNP & 0.784 & 0.043 & 0.908 & 0.028 & -0.124 & $5.82^{* *}$ \\
Past HSNP & 3.530 & 0.143 & 3.938 & 0.159 & -0.408 & $3.64 *$ \\
& & & & & & \\
IBLI & 0.719 & 0.103 & 0.518 & 0.154 & 0.201 & 1.17 \\
Past IBLI & 1.366 & 0.503 & 1.183 & 0.045 & 0.183 & $7.32 * * *$ \\
\hline
\end{tabular}

The estimated outcomes are then the result of variation in household response to the programs and variation in household participation rates across $D$. These estimates can be found in Table G2 and Table G3. One note on interpreting the following results. In cases where there is little or no heterogeneity, dividing the sample into two groups will reduce the precision of our estimates. In cases where there is heterogeneity, allowing for it should increase the precision of our estimates but the associate reduction in sample size reduces the precision so that the net impact on precision is ambiguous.

The outcomes for production strategies and related outcomes are generally consistent with the earlier parameter estimates found in Table 6, but there are an important difference revealed by allowing for heterogeneity. Although the evidence points towards similar increases in per TLU vet expenditures for the low and high TLU households, for both IBLI and HSNP participants, low TLU households see larger increases in per TLU milk income.

\footnotetext{
51 The difference in past HSNP participation amounts to 0.4 seasons of transfers (expected value of 2,740 KSH) and $12.4 \%$ reduced likelihood of current participation (expected value of $848 \mathrm{KSH}$ ). The difference in past seasons with IBLI coverage is about $15 \%$ and there is no statistically significant difference in amount of current coverage.
} 
Table G2. Estimated production impacts of HNSP and IBLI programs on participants in high and low TLU class

\begin{tabular}{|c|c|c|c|c|c|c|}
\hline \multirow[t]{2}{*}{ Dependent Variable } & \multicolumn{3}{|c|}{ HSNP } & \multicolumn{3}{|c|}{ IBLI } \\
\hline & $\begin{array}{l}\text { TLU } \\
\text { High }\end{array}$ & $\begin{array}{l}\text { TLU } \\
\text { Low }\end{array}$ & Difference & $\begin{array}{l}\text { TLU } \\
\text { High }\end{array}$ & $\begin{array}{l}\text { TLU } \\
\text { Low }\end{array}$ & Difference \\
\hline \multicolumn{7}{|l|}{ Production strategies: } \\
\hline Herd Size & $\begin{array}{l}0.195 \\
(2.889)\end{array}$ & $\begin{array}{l}-3.037 \\
(4.392)\end{array}$ & $\begin{array}{c}3.233 \\
(3.839)\end{array}$ & $\begin{array}{c}-6.874 * * \\
(2.923)\end{array}$ & $\begin{array}{c}-7.109 * * \\
(3.002)\end{array}$ & $\begin{array}{c}0.234 \\
(3.390)\end{array}$ \\
\hline Veterinary & $1,427 * *$ & 550.0 & 877.3 & 1,659 & 269.3 & 1,389 \\
\hline Expenditures (KSH) & $(692.1)$ & (339.9) & (739.8) & $(1,896)$ & $(475.2)$ & $(1,731)$ \\
\hline Veterinary & 77.49 & 106.7 & -29.19 & 143.3 & 188.0 & -44.60 \\
\hline Expenditures/TLU & (58.96) & (77.04) & $(67.23)$ & $(141.0)$ & (133.7) & (130.4) \\
\hline $\begin{array}{l}\text { Ratio of Herd Held at } \\
\text { Home }\end{array}$ & $\begin{array}{c}0.119 \\
(0.105)\end{array}$ & $\begin{array}{c}0.234 \\
(0.170)\end{array}$ & $\begin{array}{l}-0.115 \\
(0.136)\end{array}$ & $\begin{array}{l}-0.144 \\
(0.160)\end{array}$ & $\begin{array}{l}-0.127 \\
(0.221)\end{array}$ & $\begin{array}{l}-0.0169 \\
(0.189)\end{array}$ \\
\hline $\begin{array}{l}\text { Household is Partially } \\
\text { or Fully Mobile }\end{array}$ & $\begin{array}{c}0.542 * * * \\
(0.112)\end{array}$ & $\begin{array}{c}0.411^{* * *} \\
(0.156)\end{array}$ & $\begin{array}{c}0.131 \\
(0.140)\end{array}$ & $\begin{array}{c}0.108 \\
(0.179)\end{array}$ & $\begin{array}{l}-0.236 \\
(0.200)\end{array}$ & $\begin{array}{c}0.345 \\
(0.225)\end{array}$ \\
\hline \multicolumn{7}{|l|}{ Production outcomes: } \\
\hline Milk income (KSH) & $\begin{array}{l}355.0 \\
(1,524)\end{array}$ & $\begin{array}{c}1,341 \\
(1,746)\end{array}$ & $\begin{array}{l}-986.2 \\
(1,587)\end{array}$ & $\begin{array}{l}3,298^{*} \\
(1,753)\end{array}$ & $\begin{array}{l}2,255^{*} \\
(1,257)\end{array}$ & $\begin{array}{c}1,042 \\
(1,775)\end{array}$ \\
\hline $\begin{array}{l}\text { Milk income per TLU } \\
(\mathrm{KSH})\end{array}$ & $\begin{array}{l}-19.23 \\
(106.5)\end{array}$ & $\begin{array}{l}255.0^{* * *} \\
(124.8)\end{array}$ & $\begin{array}{c}-274.2 * * * \\
(97.85)\end{array}$ & $\begin{array}{l}353.5^{* *} \\
(157.7)\end{array}$ & $\begin{array}{c}669.3 * * * \\
(172.6)\end{array}$ & $\begin{array}{c}-315.7 * * \\
(153.4)\end{array}$ \\
\hline Livestock losses & $\begin{array}{c}0.722 \\
(0.643)\end{array}$ & $\begin{array}{c}0.556 \\
(0.878)\end{array}$ & $\begin{array}{c}0.166 \\
(0.780)\end{array}$ & $\begin{array}{c}-2.208^{* *} \\
(0.991)\end{array}$ & $\begin{array}{l}-0.857 \\
(0.833)\end{array}$ & $\begin{array}{l}-1.351 \\
(0.849)\end{array}$ \\
\hline $\begin{array}{l}\text { Livestock Mortality } \\
\text { Rate }\end{array}$ & $\begin{array}{l}-0.0177 \\
(0.0290) \\
\end{array}$ & $\begin{array}{l}-0.0346 \\
(0.0416) \\
\end{array}$ & $\begin{array}{c}0.0169 \\
(0.0301) \\
\end{array}$ & $\begin{array}{l}-0.0454 \\
(0.0520) \\
\end{array}$ & $\begin{array}{l}-0.00312 \\
(0.0560) \\
\end{array}$ & $\begin{array}{l}-0.0423 \\
(0.0345) \\
\end{array}$ \\
\hline $\begin{array}{l}\text { Estimates are the result of est } \\
\text { and D. Equation 1' is estimat } \\
\text { head, age of head squared, ma } \\
\text { season's predicted livestock } \\
\text { dummies and the three HSNP } \\
\text { to estimate the likelihood that } \\
\text { p }<0.01, * * p<0.05, * p<0.1 \text {. }\end{array}$ & $\begin{array}{l}\text { ating Equat } \\
\text { using hous } \\
\text { mum educat }\end{array}$ & 1' and ther & $\begin{array}{l}\text { ultiplying } \beta 1 \\
\text { and include } \\
\text { dummy indic } \\
\text { on's predicted } \\
\text { irst, second, at } \\
\text { mobile. Clust }\end{array}$ & $\begin{array}{l}\text { the head of } \\
\text { tock morta } \\
\text { d power. } \\
\text { nd robust s }\end{array}$ & $\begin{array}{l}\text { riate VOIs } \\
\text { tes: adult e } \\
\text { sehold is a } \\
\text { rate square } \\
\text { lear probab } \\
\text { ard errors i }\end{array}$ & $\begin{array}{l}\text { nd in Table G1 } \\
\text { valence, age of } \\
\text { ow, the current } \\
\text { division-period } \\
\text { y model is used } \\
\text { arentheses. *** }\end{array}$ \\
\hline
\end{tabular}

Similar to the production estimates, the welfare estimates generally coincide with our original parameter estimates with the exception of the impact of HSNP participation on school absenteeism. In the original estimates there was no statistically significant evidence the HSNP transfers reduced school absenteeism among students. Allowing for variation between TLU groups, we now find that for those in the high TLU group, HSNP transfers have a large, negative, and statistically significant impact on school absenteeism. The remaining impacts found in Table 7 continue to be evident here and appear to effect both low and high TLU groups in a fairly similar manner. In addition, allowing for heterogeneity reveals that the benefits of HSNP on MUAC are greater for those in the low TLU group. 
Table G3. Estimated welfare impacts of HNSP and IBLI programs on participants in high and low TLU class

\begin{tabular}{|c|c|c|c|c|c|c|}
\hline \multirow[b]{2}{*}{ Dependent Variable } & \multicolumn{3}{|c|}{ HSNP } & \multicolumn{3}{|c|}{ IBLI } \\
\hline & TLU High & TLU Low & Difference & TLU High & TLU Low & Difference \\
\hline Consumption per $\mathrm{AE}$ & $\begin{array}{c}-249.4 \\
(323.6)\end{array}$ & $\begin{array}{c}-227.2 \\
(384.4)\end{array}$ & $\begin{array}{c}-22.22 \\
(316.2)\end{array}$ & $\begin{array}{l}-315.4 \\
(391.2)\end{array}$ & $\begin{array}{c}-695.5 \\
(472.2)\end{array}$ & $\begin{array}{c}380.1 \\
(522.7)\end{array}$ \\
\hline Asset Index & $\begin{array}{c}-22.48^{* *} \\
(11.18)\end{array}$ & $\begin{array}{l}-25.32 * \\
(14.95)\end{array}$ & $\begin{array}{c}2.841 \\
(10.95)\end{array}$ & $\begin{array}{c}-46.75^{* *} \\
(18.39)\end{array}$ & $\begin{array}{l}-51.54 \\
(34.80)\end{array}$ & $\begin{array}{c}4.785 \\
(26.86)\end{array}$ \\
\hline Income per $\mathrm{AE}$ & $\begin{array}{c}477.1 \\
(377.6)\end{array}$ & $\begin{array}{c}629.6 \\
(398.6)\end{array}$ & $\begin{array}{l}-152.5 \\
(363.6)\end{array}$ & $\begin{array}{l}1,017^{*} \\
(523.6)\end{array}$ & $\begin{array}{l}1,007 * * \\
(399.2)\end{array}$ & $\begin{array}{c}10.04 \\
(484.1)\end{array}$ \\
\hline School Absenteeism & $\begin{array}{c}-6.090 * * \\
(2.885)\end{array}$ & $\begin{array}{l}-0.628 \\
(1.513)\end{array}$ & $\begin{array}{c}-5.462 * * \\
(2.433)\end{array}$ & $\begin{array}{l}-0.345 \\
(2.518)\end{array}$ & $\begin{array}{c}0.313 \\
(2.083)\end{array}$ & $\begin{array}{c}-0.658 \\
(2.817)\end{array}$ \\
\hline School Enrollment & $\begin{array}{c}0.0424 \\
(0.0897)\end{array}$ & $\begin{array}{l}0.0607 \\
(0.127)\end{array}$ & $\begin{array}{c}-0.0183 \\
(0.0903)\end{array}$ & $\begin{array}{l}0.0958 \\
(0.114)\end{array}$ & $\begin{array}{c}0.180 \\
(0.137)\end{array}$ & $\begin{array}{l}-0.0846 \\
(0.145)\end{array}$ \\
\hline MUAC & $\begin{array}{l}1.064 * * \\
(0.512)\end{array}$ & $\begin{array}{c}1.850 * * * \\
(0.668)\end{array}$ & $\begin{array}{l}-0.786 \\
(0.496)\end{array}$ & $\begin{array}{c}0.632 \\
(1.239)\end{array}$ & $\begin{array}{l}-0.358 \\
(1.192)\end{array}$ & $\begin{array}{c}0.990 \\
(0.943)\end{array}$ \\
\hline $\operatorname{Pr}(\mathrm{MUAC} \leq 12.5 \mathrm{~cm})$ & $\begin{array}{c}-0.331 * * * \\
(0.126) \\
\end{array}$ & $\begin{array}{c}-0.726^{* * * *} \\
(0.196) \\
\end{array}$ & $\begin{array}{c}0.395^{* *} \\
(0.161) \\
\end{array}$ & $\begin{array}{c}0.00953 \\
(0.378) \\
\end{array}$ & $\begin{array}{l}0.0153 \\
(0.313) \\
\end{array}$ & $\begin{array}{c}-0.00575 \\
(0.265) \\
\end{array}$ \\
\hline
\end{tabular}

Estimates are the result of estimating Equation 1' and then multiplying $\beta_{1}$ and $\beta_{2}$ by the appropriate VOIs found in Table G1 and $D$. Equation 1' is estimated using household fixed effects and include the following covariates: adult equivalence, age of head, age of head squared, maximum education in household, a dummy indicating the head of household is a widow, the current season's predicted livestock mortality rate, the current season's predicted livestock mortality rate squared, division-period dummies and the three HSNP targeting characteristics to the first, second, and third power. Clustered and robust standard errors in parentheses. $* * * \mathrm{p}<0.01, * * \mathrm{p}<0.05, * \mathrm{p}<0.1$.

In order to better understand if the heterogeneity in impacts of milk per TLU and in school absenteeism is due to variation in response or participation, we examine the parameter estimates of these two variables (Table G4). Here, Past refers to past participation (HSNP) or past coverage (IBLI), Current refers to current participation (HSNP) or current amount of coverage (IBLI), and $D$ is the dummy variable that is equal to one if the household is from the initial low TLU group. Thus, parameter estimates for the VOI without interactions represent the estimated average treatment response among households in the high TLU group, the interactions represent the differences between high and low TLU household in response to program participation, and the addition of the two (e.g., Past + Past*D) is the low TLU response.

For both milk income per TLU and school absenteeism, the parameter estimates for HNSP participation vary dramatically across TLU groups. For milk, the current and past coefficients offset each other among the high TLU group but are complementary in the low TLU group leading the resulting differences in impacts to be the result of variation in household response. A similar but reversed story is true for school absenteeism. Both current and past HSNP participation reduce school absenteeism for the high TLU group but the interactions almost perfectly offset those impacts so that they see no statistically significant impact.

There is evidence that the milk productivity of low TLU households responds more strongly to past IBLI coverage than do high TLU households. Beyond that, there is very evidence that the impacts of IBLI coverage change dramatically across low and high initial herd sizes. 
Table G4. Impacts of program participation, allowing for heterogeneity between high and low TLU holdings

\begin{tabular}{|c|c|c|c|c|c|c|c|c|}
\hline & \multicolumn{4}{|c|}{ HSNP } & \multicolumn{4}{|c|}{ IBLI } \\
\hline & Past & Past*D & Current & $\begin{array}{c}\text { Current } \\
* \mathrm{D}\end{array}$ & Past & Past*D & Current & Current*D \\
\hline $\begin{array}{l}\text { Milk income per TLU } \\
\text { (KSH) }\end{array}$ & $\begin{array}{l}43.69^{*} \\
(24.62)\end{array}$ & $\begin{array}{l}25.57 \\
(25.52)\end{array}$ & $\begin{array}{c}-221.2 * * * \\
(66.26)\end{array}$ & $\begin{array}{c}201.7 * * \\
(86.61)\end{array}$ & $\begin{array}{c}237.2 * * \\
(111.4)\end{array}$ & $\begin{array}{r}291.4^{* *} \\
(121.9)\end{array}$ & $\begin{array}{c}40.99 \\
(38.00)\end{array}$ & $\begin{array}{c}44.11 \\
(63.27)\end{array}$ \\
\hline School Absenteeism & $\begin{array}{l}-1.119 \\
(0.709)\end{array}$ & $\begin{array}{c}0.731 \\
(0.667)\end{array}$ & $\begin{array}{l}-2.731 \\
(3.008)\end{array}$ & $\begin{array}{l}3.721 \\
(2.882)\end{array}$ & $\begin{array}{l}-0.388 \\
(2.191)\end{array}$ & $\begin{array}{r}-0.0633 \\
(2.755)\end{array}$ & $\begin{array}{c}0.256 \\
(0.913)\end{array}$ & $\begin{array}{l}1.377 \\
(1.405)\end{array}$ \\
\hline $\operatorname{Pr}(\mathrm{MUAC} \leq 12.5 \mathrm{~cm})$ & $\begin{array}{l}-0.0459 \\
(0.0308)\end{array}$ & $\begin{array}{c}0.0282 \\
(0.0452)\end{array}$ & $\begin{array}{l}-0.188 \\
(0.131)\end{array}$ & $\begin{array}{c}-0.385^{* *} \\
(0.192)\end{array}$ & $\begin{array}{l}-0.0794 \\
(0.312)\end{array}$ & $\begin{array}{l}-0.158 \\
(0.273)\end{array}$ & $\begin{array}{c}0.0130 \\
(0.0594)\end{array}$ & $\begin{array}{c}0.0678 \\
(0.0855)\end{array}$ \\
\hline
\end{tabular}

Past refers to the number of past seasons with HSNP participation or IBLI coverage. Current is equal to one if the household is a current HSNP participant and equal to the amount of currant IBLI coverage that the household has. $\mathrm{D}=1$ if the household had ten or fewer TLUs during the initial pre-survey data collection. Estimates are the result of estimating Equation 1, which is estimated using household fixed effects and include the following covariates: adult equivalence, age of head, age of head squared, maximum education in household, a dummy indicating the head of household is a widow, the current season's predicted livestock mortality rate, the current season's predicted livestock mortality rate squared, division-period dummies and the three HSNP targeting characteristics to the first, second, and third power. Clustered and robust standard errors in parentheses. $* * * \mathrm{p}<0.01, * * \mathrm{p}<0.05, *$ $\mathrm{p}<0.1$.

For most of the outcomes that we examined here, there no little evidence that either program favors high or low TLU households. But in two cases, milk income per TLU and school absenteeism, there is some evidence of heterogeneity with respect to HSNP and in one case, milk income per TLU, the estimated impact varies with respect to IBLI. Examining the parameter estimates shows that this heterogeneity comes from variation in how responsive each of the groups is to the respective program, rather than reflecting variation in participation levels. This points towards an important dynamic for policy makers as they target interventions. 